\title{
A Tale of Two Transmitters: Serotonin and Histamine as In Vivo Biomarkers of Chronic Stress in Mice
}

\section{Melinda Hersey}

University of South Carolina

Melissa Reneaux

Imperial College London

Shane Berger

University of South Carolina

\section{Sergio Mena}

Imperial College London

Anna Marie Buchanan

University of South Carolina

Yangguang Ou

University of South Carolina

Navid Tavakoli

University of South Carolina

\section{Lawrence P. Reagan}

University of South Carolina School of Medicine

Claudia Clopath

Imperial College London

Parastoo Hashemi ( $\nabla$ phashemi@imperial.ac.uk)

Imperial College London

\section{Research}

Keywords: Serotonin, Histamine, Depression, Inflammation, Stress, Biomarkers

Posted Date: November 23rd, 2021

DOI: https://doi.org/10.21203/rs.3.rs-1062078/v1

License: (c) (1) This work is licensed under a Creative Commons Attribution 4.0 International License.

Read Full License 


\section{A Tale of Two Transmitters: Serotonin and 2 Histamine as In Vivo Biomarkers of Chronic 3 Stress in Mice}

4

5 Melinda Hersey, ${ }^{1,2^{*}}$ Melissa Reneaux, ${ }^{3^{*}}$ Shane Berger, ${ }^{1}$ Sergio Mena, ${ }^{3}$ Anna Marie

6 Buchanan, ${ }^{1}$ Yangguang Ou, ${ }^{1}$ Navid Tavakoli, ${ }^{1}$ Lawrence P. Reagan, ${ }^{2,4}$ Claudia

7 Clopath, ${ }^{3}$ Parastoo Hashemi ${ }^{1,3+}$

$8 \quad{ }^{1}$ Department of Chemistry and Biochemistry, University of South Carolina, Columbia, SC, 29208 USA

$9{ }^{2}$ Department of Pharmacology, Physiology, \& Neuroscience, University of South Carolina SOM, Columbia, SC, 1029209 USA

$11{ }^{3}$ Department of Bioengineering, Imperial College London, London SW7 2AZ, UK

$12{ }^{4}$ Columbia VA Health Care Systems, Columbia, SC, 29208 USA

15 * These authors contributed equally to the work

$16+$ To whom correspondence should be addressed:

17 Parastoo Hashemi, email: phashemi@imperial.ac.uk , hashemi@mailbox.sc.edu

18 Running title: Biomarkers of Stress-induced Depression

19 Keywords: Serotonin, Histamine, Depression, Inflammation, Stress, Biomarkers 
Abstract

21 Background: Stress-induced mental illnesses (mediated by neuroinflammation) pose one of

22 the world's most urgent public health challenges. A reliable in vivo chemical biomarker of stress

23 would significantly improve the clinical communities' diagnostic and therapeutic approaches to

24 illnesses like depression.

25 Methods: Male and female C57BL/6J mice underwent a chronic stress paradigm. We paired 26 innovative in vivo serotonin and histamine voltammetric measurement technologies, behavioral 27 testing, and cutting-edge mathematical methods to correlate chemistry to stress and behavior.

28 Results: Inflammation-induced increases in hypothalamic histamine were co-measured with 29 decreased in vivo extracellular hippocampal serotonin in mice that underwent a chronic stress 30 paradigm, regardless of behavioral phenotype. In animals with depression phenotypes, 31 correlations were found between serotonin and the extent of behavioral indices of depression.

32 We created a high accuracy algorithm that could predict whether animals had been exposed to 33 stress or not based solely on the serotonin measurement. We next developed a model of 34 serotonin and histamine modulation, which predicted that stress-induced neuroinflammation 35 increases histaminergic activity, serving to inhibit serotonin. Finally, we created a mathematical 36 index of stress, $S_{i}$ and predicted that during chronic stress, where $S_{i}$ is high, simultaneously 37 increasing serotonin and decreasing histamine is the most effective chemical strategy to 38 restoring serotonin to pre-stress levels. When we pursued this idea pharmacologically, our 39 experiments were nearly identical to the model's predictions.

40 Conclusions: This work shines the light on two biomarkers of chronic stress, histamine and 41 serotonin, and implies that both may be important in our future investigations of the pathology 42 and treatment of inflammation-induced depression. 


\section{Background}

44 Chronic stress is one of the most urgent public health issues of recent times. Predictions are

45 that in the post-COVID19 era stress-induced mental health illnesses, particularly depression,

46 will be unprecedented [1-3]. The urgency for novel therapeutics treatments, thus, cannot be

47 overstated since existing therapies, including the selective serotonin reuptake inhibitors

48 (SSRIs), do not bring clinical relief to many patients [4]. It continues to be extremely challenging

49 to develop antidepressant therapies because there are no reliable preclinical screening tests

50 that can accurately predict the outcome of lead compounds. An ideal screening tool would be

51 underpinned by a chemical hypothesis of depression, incorporate measurement of a chemical

52 biomarker of this hypothesis and the response of this biomarker to a candidate agent. A large

53 body of elegant work has supported the original monoamine hypothesis, that surmises that the

54 functionality of monoamines such as serotonin and norepinephrine are impaired during stress

55 and depression [5-9]. The more recent cytokine theory specifies that these impairments are

56 downstream chemical effects of increased immune activity (hence pro-inflammatory cytokines)

57 [10]. Both monoamines and pro-inflammatory cytokines have been pharmacologically targeted

58 with some efficacy [4, 11-14], but neither class of analytes are successful, peripheral biomarkers

59 of stress or depression that would facilitate successful diagnosis and/or drug screening [15-

60 19]. In the brain, there has traditionally been a lack of analytical tools to provide temporally,

61 spatially and chemically relevant measurements to probe theory specific biomarkers.

62 In this work, we combine niche, in vivo voltammetric serotonin measurement tools and cutting-

63 edge machine learning with mathematical modelling to test the intersection of the monoamine

64 and cytokines theories in a model of chronic stress in mice. We report a significant reduction in

65 extracellular serotonin in the hippocampus in all mice that underwent the chronic stress

66 paradigm, regardless of behavioral phenotype. A machine learning algorithm was able to

67 successfully classify animals as stressed versus non-stressed based solely on this single 
serotonin measurement. Excitingly, in animals that displayed depressive-like phenotypes, the magnitude of some behavioral indices of depression correlated well with extracellular serotonin.

70 The nexus of monoamines and inflammation was next studied via a computational model

71 revealing a bidirectional modulation between serotonin and histamine, a well-known mediator of

72 peripheral inflammation. The model predicted, and we experimentally validated, that stress-

73 induced inflammation increased histaminergic activity in the brain serving to inhibit serotonin via

$74 \mathrm{H} 3$ receptors. The model revealed the critical importance of histamine in modulating serotonin

75 under stress. We next married the correlative relationships between serotonin and behavior to

76 histamine's modulation of serotonin to create a mathematical index of stress, which we coin $S_{i}$,

77 that serves to stratify the chronically stressed mice. The model predicted that when $S_{i}$ was high

78 (high level of stress), this index could be lowered by simultaneously increasing serotonin and 79 decreasing histamine. When pharmacologically performing these experiments suggested by the

80 model, we were able to near-perfectly replicate the model's predictions and reinstate normal 81 extracellular serotonin.

82 Our work bridges the two major theories of depression, offering biomarkers for stress and novel 83 pharmacological strategies based on histamine.

\section{Methods \& Materials}

\section{Chemicals, Reagents, and Assays}

86 Calibration solutions were prepared by dissolving serotonin hydrochloride (Sigma-Aldrich Co.,

87 St. Louis, MO, USA) in Tris buffer to produce solution concentrations of 10, 25, 50, and $100 \mathrm{nM}$.

88 Tris buffer consisted of: $15 \mathrm{mM} \mathrm{H}_{2} \mathrm{NC}\left(\mathrm{CH}_{2} \mathrm{OH}\right)_{2} \mathrm{HCl}, 140 \mathrm{mM} \mathrm{NaCl}, 3.25 \mathrm{mM} \mathrm{KCl}, 1.2 \mathrm{mM}$

$89 \mathrm{CaCl}_{2}, 1.25 \mathrm{mM} \mathrm{NaH}_{2} \mathrm{PO}_{4} \cdot \mathrm{H}_{2} \mathrm{O}, 1.2 \mathrm{mM} \mathrm{MgCl}_{2}$, and $2.0 \mathrm{mM} \mathrm{Na}_{2} \mathrm{SO}_{4}$ (Sigma-Aldrich Co., St.

90 Louis, MO, USA) in deionized water and $\mathrm{pH}$ adjusted to 7.4. Pharmacological agents were

91 prepared as described below. Escitalopram oxalate (10 mg kg-1, Sigma-Aldrich, St. Louis, MO, 
92 USA) and a-fluoromethylhistidine dihyrdrochloride (20 mg kg-1, Toronto Research Chemicals

93 Inc., Toronto, CAN) were dissolved in saline individually (Hospira, Lake Forest, IL, USA). All

94 pharmaceutical agents were administered via intraperitoneal (i.p.) injection at a volume of $5.0 \mathrm{ml}$

$95 \mathrm{~kg}^{-1}$ of animal weight. A bioplex was used to analyze cytokines (Bio-Rad Laboratories, Hercules, 96 CA, USA) in plasma at sacrifice.

\section{Electrode Fabrication}

98 Carbon fiber microelectrodes (CFMs) were made as previously described [20]. Briefly, a single 99 carbon fiber $(7 \mu \mathrm{m}$, Goodfellow, Corporation, Coraopolis, PA, USA) was aspirated into a glass 100 capillary (0.6 mm OD, $0.4 \mathrm{~mm}$ ID, $10 \mathrm{~cm}$ length; A-M Systems, Sequim, WA, USA) and sealed 101 under gravity and heat by vertical pipette puller (Narishige Group, Tokyo, JAP). Exposed fibers 102 were trimmed to $150 \mu \mathrm{m}$ under light microscope and silver paint was used to forge an electrical 103 connection to a connection pin. Finally, electrodes were electrodeposited with Nafion ${ }^{\mathrm{TM}}$ (LQ104 1105, Ion Power Solutions, New Castle DE, USA) as previously described [20].

\section{Animals}

106 All animal procedures and protocols were performed in accordance with regulations of the 107 Institutional Animal Care and Use Committee (IACUC) at the University of South Carolina, 108 which operates with accreditation from the Association for Assessment and Accreditation of 109 Laboratory Animal Care (AAALAC). Male and female C57BL/6J mice (Jackson Laboratory, Bar 110 Harbor, ME, USA), arrived at 6-7 weeks old group housed, with ad libitum access to food and 111 water, and were kept on a $12 \mathrm{~h}$ light/12 $\mathrm{h}$ dark cycle (lights off at 7:00 and on at 19:00). A 112 chronic unpredictable mild stress paradigm (CMS) was conducted over a 16-week period and 113 based on previously documented models [21-24]. Two to three mild stressors were performed a 114 day. Stressors included: food or water deprivation, confinement, cage tilt, soiled cage, light 115 during dark cycle, bedding removal, novel object, handling. All stressors were stopped during 116 behavior testing and $12 \mathrm{hrs}$ leading up to neurochemical studies. 


\section{Behavioral Testing}

118 Following the CMS behavioral paradigm, animals underwent previously established behavioral 119 testing for anxiety and depressive-like phenotypes [25]. In a sucrose preference test (SPT), 120 mice were exposed to bottles with water and water with a $1 \%$ sucrose solution (Sigma-Aldrich, 121 St. Louis, MO, USA). Water was removed at midnight and then water and water/sucrose was 122 placed at 7:00, water and water/sucrose solutions were weighed before administration, one hour 123 after placement (8:00), three hours after placement (11:00), and twelve hour after placement 124 (19:00). The test was completed twice, first as a pretest and second as test. An elevated zero 125 maze (EZM) was conducted as previously described [26]. Each mouse was placed into the 126 closed arm of the apparatus (Maze Engineers, Boston, MA, USA) and allowed to explore for 5 127 min. Time spent in the closed arm was measured as an indicator of anxiety-like behavior. A 128 forced swim test (FST) was conducted as described in Yankelevitch-Yahav et al. [27]. In brief, 129 mice were placed in containers filled with water and behavior was observed for 6 min total (the 130 first 2 min were classified as pretest and remaining 4 min were the test). Tail suspension test

131 (TST) was completed as previously described [28]. Each mouse's tail was attached via tape to 132 the rod and a small plastic, flexible tube was placed on the tail to limit climbing behavior within 133 the apparatus (Maze Engineers, Boston, MA, USA) for the duration of the 6 min test. Percent 134 immobility was measured in the first 2 min (pretest) and the remaining 4 min (test). Rodent 135 behavior was analyzed using Noldus EthoVision (Leesburg, VA, USA).

\section{Surgical Procedures}

137 Surgery was performed following an i.p. injection of $25 \% \mathrm{w} / \mathrm{v}$ urethane $(7 \mu \mathrm{l} / \mathrm{g}$ of body weight) 138 (Sigma-Aldrich Co., dissolved in $0.9 \% \mathrm{NaCl}$ solution, Hospira, Lake Forest, IL, USA) to maintain 139 and induce anesthesia. Mouse body temperature was maintained using a heating pad 140 (Braintree Scientific, Braintree, MA, USA). Stereotaxic surgery (David Kopf Instruments, 141 Tujunga, CA, USA) was performed, and all coordinates were taken in reference to bregma. A 
142 Nafion $^{\mathrm{TM}}$-modified CFM was lowered into the CA2 region of the hippocampus (5HT: AP: -2.91,

143 ML: +3.35, DV: -2.5 to -3.0 ) or the posterior hypothalamus (HA: AP: -2.45 , ML: +0.5 , DV: -5.45

144 to -5.55 ) [29] and adjusted until a serotonin/histamine signal was observed. A stimulating 145 electrode (insulated stainless steel, diameter: $0.2 \mathrm{~mm}$, untwisted, Plastics One, Roanoke, VA, 146 USA) was placed into the medial forebrain bundle (5HT: AP: -1.58, ML: +1.00, DV: -4.8 ) or (HA: 147 AP: -1.07, $\mathrm{ML}:+1.10, \mathrm{DV}:-5.0)$ [29] and a pseudo $\mathrm{Ag} / \mathrm{AgCl}$ reference electrode, created by 148 electroplating chloride $(30 \mathrm{~s}$ in $0.1 \mathrm{M} \mathrm{HCl}$ at $5 \mathrm{~V}$ ) onto a silver wire, was placed into the 149 contralateral hemisphere.

\section{Voltammetric Data Collection and Analysis}

151 FSCV and FSCAV were performed using a Dagan potentiostat (Dagan Corporation, 152 Minneapolis, NM, USA), WCCV 3.06 software (Knowmad Technologies LLC, Tucson, AZ, 153 USA), a Pine Research headstage (Pine Research Instrumentation, Durham, NC, USA), and 154 National Instruments DAQ cards $\mathrm{NI}-6341$ and $\mathrm{NI}-6221$ (NI, Austin, TX, USA). For FSCV 155 collection, the "Jackson" serotonin waveform [30] was applied to the electrode at a scan rate of $1561000 \mathrm{~V} \mathrm{~s}^{-1}$ and at a frequency of $10 \mathrm{~Hz}$ or the histamine waveform, was applied at a scan rate of $157600 \mathrm{~V} \mathrm{~s}^{-1}$ and at a frequency of $10 \mathrm{~Hz}$ [31]. To evoke serotonin or histamine release, a biphasic 158 stimulation was applied through a linear constant current stimulus isolator (NL800A Neurolog, 159 Medical Systems Corp, Great Neck, NY, USA) with the following parameters: $60 \mathrm{~Hz}, 360 \mu \mathrm{A}$ 160 each, $2 \mathrm{~ms}$ in width, and $2 \mathrm{~s}$ in length. Four control files of serotonin or histamine were collected $16110 \mathrm{~min}$ apart for each animal prior to injection of pharmacological agents. Following voltammetry 162 data collection, a high voltage was applied to the CFM to lesion the tissue around the electrode 163 which enables electrode placement verification in post-mortem histological analyses.

164 For basal experiments, control evoked files were collected followed by the methodology being 165 switched to FSCAV. For FSCAV collection, the serotonin waveform was applied at $100 \mathrm{~Hz}$ for 2 $166 \mathrm{~s}$, followed by a period of controlled adsorption where the potential was held at $0.2 \mathrm{~V}$ for $10 \mathrm{~s}$, 
167 lastly the serotonin waveform was reapplied at $100 \mathrm{~Hz}$, as described in Abdalla et al. [32]. Thirty 168 files (at one file per minute) were collected as control files. Following control files, an i.p. 169 injection of saline and then ESCIT $\left(10 \mathrm{mg} \mathrm{kg}^{-1}\right)$ i.p. was administered and 30 or 60 FSCAV files 170 were collected respectively post-treatment. The system was then switched back to traditional 171 FSCV and four post-basal stimulation files were collected. Electrodes were then removed and 172 underwent a post calibration in solutions of serotonin.

173 Data were analyzed using WCCV software digital filtration (zero phase, Butterworth, $5 \mathrm{kHz}$ low174 pass) and smoothing. For FSCV analysis, the cyclic voltammogram (CV) was used for both 175 histamine and serotonin and the current vs. time (IT) was extracted to resolve release and 176 reuptake of both neurotransmitters. A previously established calibration factor $(49.5 \pm 10.2$ $177 \mathrm{nA} / \mu \mathrm{M})$ for serotonin analysis [20] and $2.825 \mu \mathrm{M} / \mathrm{nA}$ for histamine and $11 \mathrm{nM} / \mathrm{nA}$ for serotonin 178 were used to convert current to concentration [31, 33].

179 For FSCV data, four IT curves were averaged for each animal to establish a control. The 180 average for each individual animal was then combined with the other animals in the group to 181 determine an overall group average. The standard error of the mean (SEM) was calculated 182 using the average IT for each animal ( $n=$ \# animals).

183 For FSCAV analysis, the third CV after the reapplication of the waveform was selected for 184 quantification, and the peak occurring approximately between 0.4 and $0.85 \mathrm{~V}$ was integrated to 185 determine the charge value $(p C)$. Post calibrations of each electrode, plotting charge $(p C)$ vs. 186 [serotonin] (nM), were used to determine basal concentration.

187 Animals were excluded if signals were determined to be outliers via the Grubbs test for outliers 188 or if they did not survive the experimental paradigm. To determine the $t_{1 / 2}$, a code was custom 189 written in excel to fit the reuptake component of the curve and calculate the time taken to reach 190 half of the maximum amplitude. Area under the curve was analyzed via Simpson's rule with 191 Python. 


\section{Computational Model}

193 The bidirectional interaction of histamine and serotonin following chronic stress exposure 194 depression has been modelled (Figure 3C).

195 Here, HA and 5HT denote the histamine and serotonin concentration pool in the hypothalamus

196 respectively. $\mathrm{T}_{\mathrm{HA}}$ and $\mathrm{T}_{5 \mathrm{HT}}$ are the decay or reuptake time constants of histamine and serotonin 197 respectively. $\alpha$ is the rate of increase in histamine levels due to serotonin and $\beta$ is rate of 198 decrease in serotonin levels due to histamine. $\mathrm{I}_{5 \mathrm{HT}}$ and $\mathrm{I}_{\mathrm{HA}}$ are the tonic supply of serotonin and 199 histamine through other factors.

\section{Parameter Estimation}

201 The parameters of the model have been obtained from the experimental data collected from 202 Samaranayake et al. [33]. The peak responses of histamine and serotonin transients under 203 variation in electrical stimulation amplitude have been used for the steady state analysis and 204 parametrization of the system. The empirical impact of the increase in stimulation amplitude on 205 the physiological dynamics has been modelled through increase in the tonic histamine supply, $206 \mathrm{I}_{\mathrm{HA}}$.

207 Further, the model has been extended to predict the impact of stress-induced depression on the 208 serotonergic levels in hippocampus. Since, it is not possible yet to simultaneously measure 209 histamine alongside serotonin in the hippocampus. Therefore, based on the established model 210 we computed the concentrations of histamine (Supplementary Figure S1). Utilizing the nullcline 211 analysis as before, the parameters have been re-tuned slightly to capture the dynamics well. 212 The magnitude of these parameters is listed in Table S1. 


\section{Stress Index $\left(\mathbf{S}_{\mathbf{i}}\right)$}

214 A scalar function, defined as Stress index $\left(S_{i}\right)$, was formulated as a positive-valued function 215 scaled at zero for control and increasing positive values for stress. This function was 216 constructed with the following biological constraints:

217 1) Histamine is equal to basal brain histamine in controls or higher during stress.

218 2) Decrease in serotonin from its basal level intensifies the stressed condition caused by 219 increase in histamine. On the other hand, serotonin levels above basal level alleviates stress 220 caused by rise in histamine level.

$$
S_{i}=\Theta\left(\frac{[H A]-[H A]_{b}}{[H A]_{b}}\right)\left(\frac{[H A]-[H A]_{b}}{[H A]_{b}}\right) e^{-\gamma\left(\frac{[5 H T]-[5 H T]_{b}}{[5 H T]_{b}}\right)}
$$

221 Here, $\Theta$ is the Heaviside function, $[H A]_{b}$ and $[5 H]_{b}$ denote the basal histamine and serotonin 222 concentration respectively, $\gamma$ is the strength of cooperativity/antagonism by serotonin towards 223 stress, $[H A]$ is the level of histamine and $[5 H T]$ is the serotonin level.

\section{Sensitivity Analysis}

225 The model is formulated in the vector form as,

$$
\frac{d x}{d t}=f(x(t), p)
$$

226 Here, $x$ represents the vector of histamine and serotonin concentrations, $f$ is the vector function 227 describing the system's dynamics, and $p$ is the parameter of interest under local fluctuation. At 228 the steady state of system,

$$
0=f(x(p), p)
$$

229 Differentiation with respect to $p$ gives,

$$
0=\frac{\partial f}{\partial x} \frac{d x}{d p}+\frac{\partial f}{d p}
$$


230 Thus, the absolute sensitivity can be obtained as,

$$
\frac{d x}{d p}=-\left[\frac{\partial f}{\partial x}\right]^{-1} \frac{\partial f}{\partial p}
$$

231 Here, $\left[\frac{\partial f}{\partial x}\right]$ refers to the Jacobian of the vector function. The relative sensitivity $\frac{d x / x}{d p / p}$ is 232 obtained by normalizing the absolute sensitivity with respect to the state of the system.

\section{Clustering based on hippocampal serotonin levels}

234 To predict the state of the animal as stressed vs. non-stressed, the extracellular concentrations 235 of hippocampal serotonin in a mice population (non-stress controls and CMS mice) was 236 clustered using k-means clustering technique, with $\mathrm{k}=2.80 \%$ of the population data was used 237 to train the clustering model in an unsupervised manner and the remaining $20 \%$ of the data was 238 used for testing how well the fitted model classified the data. To compute the efficiency of the 239 clustering model, we ran 1000 independent trials with random shuffling of the data and note the 240 frequency of correct classification of the data.

\section{Statistics}

242 All data are presented as the average with the standard error of the mean (SEM). Significance 243 was determined between two points using a 2-tailed student's t-test and significance was 244 defined and denoted as * $=p<0.05$.

245 For FSCV data, the calculated area under the curve (AUC) of histamine evoked traces was 246 tested to not be drawn from a Gaussian distribution using a Shapiro-Wilk. Analysis was then 247 completed using a Wilcoxon rank sum test (Figure 3E).

248 FSCAV data was analyzed using both qualitative and quantitative statistical studies to compare 249 extracellular hippocampal serotonin for the different treatment conditions. Differences in 250 baseline serotonin concentration between control mice and CMS mice (Figure 7B) were 251 evaluated by analyzing the distribution of the differences between the time series. Figure S6 A- 
252 C shows the histograms of the differences between baseline serotonin concentration for the 3 253 groups of mice described in Figure 7B. Shapiro-Wilk tests were used to test for normality of the 254 distribution of the differences. The test failed in all cases on providing enough evidence to 255 consider the differences to be drawn from a non-Gaussian distribution $(p=0.8362, p=0.9458$ 256 and $p=0.5465$, respective to appearance on Supplementary Figure S6). The Levene test was 257 used to assess the equality of variance between the three distributions, failing to reject the null 258 hypothesis of equality of variance $(p=0.3271)$. Two-tailed Student's t-test assuming equal 259 variance were then used to compare the distributions. Differences in baseline serotonin 260 concentration between control mice and CMS mice were found to be significantly higher than 261 differences between two cohorts of CMS mice $(p<0.0001$ between distributions shown in 262 Figure S6 A and Figure S6 C, and $p<0.0001$ between distributions shown in Figure S6 B and 263 Figure S6 C). This confirmed that basal serotonin concentration for CMS mice was lower than 264 control mice prior to any treatment.

265 Bland-Altman plots were obtained to assess the reproducibility of the signal after saline 266 injection. Figure S6 D-F shows the Bland-Altman plots for the three different acquisitions 267 described in Figure 7B. No proportional or systematic errors were detected between the initial 26830 points $(0-30 \mathrm{~min})$ and the following 30 time points after saline injection $(30-60 \mathrm{~min})$. This 269 confirmed that saline injections did not have any significant impact on the serotonin 270 concentration measurements.

271 Linear regression analysis was used to model the rate of change of extracellular hippocampal 272 serotonin after treatment $(60-120 \mathrm{~min})$ for both control and CMS mice (Figure 7B). 273 Supplementary Figure $\mathbf{S 7}$ shows the analysis used to assess the goodness of the fittings. 274 Before any statistical comparison between slopes, the quality of the fittings was assessed by 275 measuring the coefficient of determination and the confidence limits of the models. In all cases, 276 basal serotonin concentration after ESCIT and ESCIT together with FMH administration 
277 followed a linear increase over time. Analysis of covariance (ANCOVA) and Tukey post hoc

278 tests were then used to compare the rate of increase of change of serotonin concentration for 279 control and CMS mice (Figure 7B). Table S2 and Table S3 show the mean estimated slopes 280 for each of the time series included in the ANCOVA test and the results obtained. Table S4 281 shows the results of the post hoc pairwise tests. The rate of increase of 5-HT after ESCIT and 282 FMH administration for CMS mice was found to be significantly higher than the rate of increase 283 after ESCIT administration for either control or CMS mice ( $p<0.0001$ in both cases). Equally, 284 the rate of increase of serotonin was also found to be higher after ESCIT administration for 285 control mice compared to CMS mice $(p<0.0001)$. No differences in slope were found between 286 any of the baseline measurements $(0-30 \mathrm{~min})$ and after saline injection $(30-60 \mathrm{~min})$, which 287 corroborated the lack of a significant impact of saline injection.

288 A two-way ANOVA (with factors of sex and type of mice) and Tukey-Kramer post hoc analyses 289 were used to reveal significant changes in behavioral test scores and cytokine concentration 290 measurements. A summary of the results is given in Table S5 and Table S6-11. More detailed 291 methods and statistical results can be found in Supplementary Information.

\section{Results}

\section{Serotonin and the Monoamine Theory in a Chronic Mild Stress Paradigm}

294 To test serotonin's roles in the monoamine theory, we utilized the unpredictable chronic mild 295 stress (CMS) paradigm [34]. In a representative cohort of mice that underwent 16 weeks of 296 stressors (Figure 1A), behavioral analyses for anxiety (EZM) and depression (SPT, TST and 297 FST) were assessed (Figure 1B-E). For the SPT (Figure 1B), significantly less sucrose 298 preference was only found in male mice after $12 \mathrm{hrs}$ (Con: $88.31 \pm 0.92 \%$; CMS: $83.33 \pm 1.42 \%$; $299 p=0.0087)$. For the EZM (1C) CMS-treated mice spent significantly more time in the closed arm 300 of the maze than control mice $(249.83 \pm 2.76 s, 230.09 \pm 3.79 s$ respectively; $p<0.0001)$ 301 (Figure 1C). For the FST only male mice showed fewer active behaviors after CMS (Con: 41.36 
$302 \pm 8.05 \%$; CMS: $66.14 \pm 9.13 \% ; p=0.0413$ ) (Figure 1D). There were no significant differences 303 between control and CMS mice in the TST despite a clear trend $(65.64 \pm 4.17 \%, 70.50 \pm 3.57 \%$ 304 respectively; $p=0.3720$ ) (Figure 1E). Approximately $74.36 \%$ of animals showed anxiety-like 305 phenotypes in the EZM and $41.03 \%$ of animals showed depression-like phenotypes after 12 306 hours in the SPT, $76.92 \%$ in the FST, and $44.44 \%$ in TST. Additional results from behavioral 307 testing can be found in Table S5.

308 In the CA2 region of the hippocampus of these same mice, we next measured evoked serotonin 309 with fast scan cyclic voltammetry (FSCV) and ambient, extracellular serotonin with fast scan 310 adsorption-controlled voltammetry (FSCAV). There was no difference in evoked serotonin 311 between control and CMS mice (Figure 2A-E). Using FSCAV we found a significant difference 312 in basal or ambient serotonin in this region (Figure $2 \mathrm{~F}-\mathrm{H}$ ), every single mouse that underwent 313 the chronic stress paradigm had decreased ambient serotonin relative to controls (control: 63.17 $314 \pm 0.34 \mathrm{nM}$, CMS: $46.70 \pm 0.26 \mathrm{nM}$; t-test, $\mathrm{p}<0.0001$ ), whether they were behaviorally 315 depressed, or resilient.

316 Using k-means clustering, a machine learning technique, on the ambient serotonin data we 317 found that the mice are well clustered into two categories: control versus CMS (Figure 2I). Via 3181000 independent runs of the clustering algorithm with random shuffling of the data, we 319 observed that the clustering almost $90 \%$ of the times correctly stratifies the mice.

320 Next, we plotted indices of behavior versus basal serotonin concentrations, fitted a linear 321 regression and calculated the Pearson's correlation coefficient (R value of the fit) (Figure $2 \mathrm{~J}$ ). 322 Blue markers are control mice and gray markers are CMS mice. R values for sucrose 323 preference at $1 \mathrm{~h}$ were $0.251,0.600$ for time spent in the closed arms of the EZM, 0.754 for 324 immobility in the FST and 0.0541 for active time in the TST. Importantly the serotonin 325 concentration in CMS mice cluster towards the high depressive-like behavior end of the scale of 326 all behaviors. 


\section{Inflammation-Induced Histamine's Modulation of Serotonin}

328 To probe how serotonin is modulated in the cytokine theory, we first performed plasma 329 cytokines analysis from the same CMS and control mice (Figure 3A, same mice as in Figures

3301 and 2). We found no significant difference in peripheral cytokine concentration between CMS 331 and control mice, however there was significance when the ratios of proinflammatory cytokines 332 to anti-inflammatory cytokines were compared, for example with TNF-a / IL-4 in females (Con: $33315.18 \pm 0.93 \mathrm{pg} / \mathrm{mL} ; \mathrm{CMS}: 19.30 \pm 1.30 \mathrm{pg} / \mathrm{mL} ; \mathrm{p}=0.0096)$. CMS-treated mice also had a trend 334 towards an increase in IL-6/IL-4 ratios ( $p=0.3741$ and 0.4497 in male and female mice).

335 Next, we turned to histamine. We constructed a mathematical model based on previously 336 published data, showing a concentration-dependent histaminergic inhibition of serotonin in the 337 posterior hypothalamus (Figure 3B) [33]. In the model, the change of histamine concentration 338 with time $(\mathrm{dH} / \mathrm{dt})$ depends on histamine clearance $\left(-\mathrm{HA} / \tau_{\mathrm{HA}}\right)$, positive modulation of histamine by 339 serotonin $(+\alpha 5 \mathrm{HT})[35]$ and constant histamine supply from glia, mast cells, neurons, $\left(\mathrm{I}_{\mathrm{HA}}\right)$ 340 (Equation 1). The change of serotonin (d5HT/dt) in turn depends on serotonin clearance ($\left.3415 \mathrm{HT} / \mathrm{T}_{5 \mathrm{HT}}\right)$, negative modulation of serotonin by histamine $(-\beta \mathrm{HA})[33,36]$ and constant ambient 342 serotonin $\left(I_{5 \mathrm{HT}}\right)$ (Equation 2). We performed parameterization of the model using nullcline 343 analysis (Figure 3C). The 5HT-nullcline (blue) consists of the set of points where serotonin 344 does not change $(\mathrm{d} 5 \mathrm{HT} / \mathrm{dt}=0)$. The HA-nullclines (orange) are the set of points where 345 histamine does not change $(\mathrm{dHA} / \mathrm{dt}=0)$. The rightward orange HA-nullcline lines are for 346 increasing values of $\mathrm{I}_{\mathrm{HA}}$. The black solid markers are the points where the $5 \mathrm{HT}$ - and HA-

347 nullclines intersect and these points are the steady states of the system for different values of $348 \mathrm{I}_{\mathrm{HA}}$, which means that both histamine and serotonin does not change any longer. We then 349 plotted the steady-states generated by the model (black solid markers) superimposed over 350 experimental data, showing excellent agreement $\left(r^{2}=0.93\right)$ (Figure 3E). The model put forth a 351 hypothesis for the decreased serotonin level (as in CMS mice) as a function of elevated 
352 histamine level (illustrated by Figure 3C). We tested this notion experimentally and found in

353 CMS mice a non-significant increase in histamine release in the hypothalamus (Con: $4.28 \pm$ $3540.51 \mathrm{uM}$; CMS: $5.64 \pm 0.66 u M$; t-test; $p=0.1300)$ and a significant increase in area under the 355 histamine release curve (Con: $14.51 \pm 2.34$; CMS: $25.46 \pm 2.80$; Wilcoxon rank sum test; $p=$ 356 0.0249). (Figure 3E).

\section{Histamine Clearance Predominantly Mediates Low Extracellular Serotonin}

358 We next conducted a global parameter sensitivity analysis on two conditions of the model 359 system, control, healthy state with a basal value of $\mathrm{I}_{\mathrm{HA}}$ (Figure 4A) and the stress condition with 360 a higher value of $\mathrm{I}_{\mathrm{HA}}, 20 \mu \mathrm{Ms}^{-1}$ (approximately 10-fold higher than the steady-state ambient 361 histamine) (Figure 4B) [37]. Parameters were varied independently (on the x-axis) from their 362 respective basal value (based on nullcline analysis). The resulting \% change in serotonin and 363 histamine from their ambient ( $y$-axis). Histamine and serotonin decay rate, $\mathrm{T}_{\mathrm{HA}}$ and $\mathrm{T}_{5 \mathrm{HT}}$, and the 364 tonic supply of serotonin, $I_{5 \mathrm{HT}}$, greatly impacted the system (largest $\%$ change from 0 ). This was 365 less the case for the serotonin-to-histamine coupling $(\alpha)$ and the histamine-to-serotonin coupling $366(\beta)$. To uncover how sensitive the system was to a given parameter in control and stressed 367 conditions, we performed a local sensitivity analysis (how small fluctuations affect the system) 368 (Figure 4C and D). We observed, for both conditions, that serotonin is far more sensitive to 369 small parameter fluctuations than histamine. In this local sensitivity analysis, the most important 370 parameters are the histamine decay rate of (or reuptake rate) $\mathrm{T}_{\mathrm{HA}}$, the serotonin-to-histamine 371 coupling $\alpha$ and tonic supply of histamine $\mathrm{I}_{\mathrm{HA}}$. All three of them, especially the histamine decay 372 rate, have a remarkably strong influence on serotonin. A slight change in these parameters led 373 to a small increase in histamine (orange bars), consistent with our expectations. Strikingly, 374 however, was the effect on serotonin (blue bars) of the change in these parameters of orders of 375 magnitude higher than the effect on histamine. 
377 We next developed a novel general measure, the 'Stress Index' $\left(\mathrm{S}_{\mathrm{i}}\right)$ based on the correlative 378 relationships in Figure 2 and our serotonin/histamine model. $S_{i}$ is a scalar function that 379 correlates stress to chemistry in mice (Figure 5A), only taking positive values. We utilized the 380 same principles of the hypothalamic co-modulation model because of the well-established 381 presence of inhibitory $\mathrm{H}_{3}$ hetero-receptors on serotonin terminals in the hippocampus [38, 39].

$382 S_{i}=0$ refers to normal (healthy) behavioral phenotypes and increasing values of $S_{i}$ indicate 383 more intense stress condition. The $S_{i}$ index (Equation 3) was constructed with the following 384 biological constraints, based on prior experiments. 1) Histamine concentration (HA) is equal to 385 ambient hypothalamic histamine $\left(\mathrm{HA}_{b}\right)$, (i.e. control models) or higher (i.e. stress models). 2) 386 Decrease in serotonin concentration $(5 \mathrm{HT})$, below ambient serotonin concentration $\left(5 \mathrm{HT}_{\mathrm{b}}\right) \mathrm{due}^{\mathrm{s}}$ 387 to increase in histamine, correlates to behavior (see regressions in Figure $\mathbf{2} \mathbf{J}$ ), thus restoring 388 ambient serotonin and histamine back to basal values will decrease $S_{i}$

$$
S_{i}=\Theta\left(\frac{[H A]-[H A]_{b}}{[H A]_{b}}\right)\left(\frac{[H A]-[H A]_{b}}{[H A]_{b}}\right) e^{-\gamma\left(\frac{[5 H T]-[5 H T]_{b}}{[5 H T]_{b}}\right)} \quad \text { Equation } 3
$$

390 where $\mathrm{\gamma}$, represents the strength of serotonin-histamine cooperation-antagonism (Supplementary 391 Figure S3A), $[\mathrm{HA}]_{\mathrm{b}}$ and $[5 \mathrm{HT}]_{\mathrm{b}}$ represent the basal ambient hypothalamic histamine and 392 serotonin levels respectively and, $[\mathrm{HA}]$ and [5HT] represent the hypothalamic steady-state 393 histamine and serotonin levels. In the model for the hypothalamus the parameters have the 394 values $\mathrm{y}=1,[5 \mathrm{HT}]_{\mathrm{b}}=41.6 \mathrm{nM}$ and $[\mathrm{HA}]_{\mathrm{b}}=3.32 * 10^{3} \mathrm{nM}$.

\section{Using $S_{i}$ to Suggest Pharmacological Approaches}

396 Previously, we studied the parameter sensitivity of serotonin and histamine. Now we use the 397 model to predict the parameter sensitivity of $S_{i}$ and therefore behavior. We perturbed the model 
parameters independently and observed that $\mathrm{T}_{\mathrm{HA}}, \alpha$ and $\mathrm{I}_{5 \mathrm{HT}}$ had great impact on the system

399 (Supplementary Figure S4) and on $\mathrm{S}_{\mathrm{i}}$ (Supplementary Figure S5). The increase in serotonin is 400 effectuated by an increase in the constant ambient serotonin $\left(I_{5 \mathrm{HT}}\right)$ or through rapid clearance of 401 histamine, $\mathrm{T}_{\mathrm{HA}}$ (Supplementary Figure $\mathbf{S 4 H}$ ). Furthermore, a decrease in $\mathrm{T}_{\mathrm{HA}}$ decreases $\mathrm{S}_{\mathrm{i}}$. Thus, 402 importantly, the model suggested that an increase in serotonin may be achieved either directly 403 via serotonin or indirectly via a decrease in histamine.

404 In the context of directly targeting serotonin, the effect of escitalopram (ESCIT), a popular SSRI, 405 was mimicked through a simultaneous decrease in histamine and serotonin reuptake rates 406 (since ESCIT inhibits both serotonin and histamine transport) [40] achieved via increasing $\mathrm{T}_{\mathrm{HA}}$ 407 and $\mathrm{T}_{5 \mathrm{HT}}$ (Figure $\mathbf{6 A}$ and $\mathbf{B}$ ). The surface (Figure 6) illustrates the impact of altering histamine 408 and serotonin reuptake together on $S_{i}$. The white solid markers on the surfaces represent $S_{i}$ for 409 basal values of $\mathrm{T}_{\mathrm{HA}}$ and $\mathrm{T}_{5 \mathrm{HT}}$ for control and stress conditions. In both the control and stressed 410 conditions, the model predicts that ESCIT administration will cause an increase in $S_{i}$ (via 411 reduction in serotonin, counter to theory), precisely because of ESCIT's effect on histamine (as 412 described above, small changes in histamine causes large changes in serotonin). The surface

413 for the stress condition has a higher basal level of histamine that allows $S_{i}$ to reach 4-fold 414 higher. We next probed which conditions would restore $S_{i}$ to lower levels and found this 415 achievable by reducing tonic histamine supply, $\mathrm{I}_{\mathrm{HA}}$ (Figure 6C).

\section{Pharmacologically targeting histamine and serotonin to restore stress-induced}

\section{7 changes in serotonin}

418 Finally, we asked the model how to restore serotonin levels in the stress conditions to healthy 419 levels. We hypothetically considered two representative populations in our model. Control mice 420 were characterized via basal parameter values for the healthy state and the blue line in Figure 4217 shows the basal extracellular serotonin level in this hypothetical control cohort. Stress mice 422 were characterized by increased tonic histamine supply, $\mathrm{I}_{\mathrm{HA}}$ (thus decreased serotonin), 
423 represented by the gray line. So far (Figure 6), the model assumed an equal affinity of ESCIT

424 for inhibiting the serotonin and histamine transporters. ESCIT has much higher affinity for the 425 serotonin transporters than for histamine transporters (the organic cation transporters) [40].

426 Therefore, we modeled effect of ESCIT as a two-fold increase in the parameter serotonin decay

427 rate $T_{5 H T}$ and as a modest increase in the histamine decay rate $T_{H A}\left(1.25 T_{H A}\right)$, more closely 428 representing the off-target effect of ESCIT on histamine re-uptake. These parameters caused a 429 significant increase in serotonin level in both control and stress conditions. Importantly ESCIT 430 did not restore serotonin levels to pre-stress levels in stress mice. The model hypothesized that 431 these reduced serotonin levels in stress mice could be brought closer to control levels by 432 simultaneously decreasing $\mathrm{I}_{\mathrm{HA}}$ and increasing serotonin with ESCIT (purple line). Figure 7A, 433 thus, is the model's hypothesis to our question of how to restore serotonin levels in the stress 434 states to healthy levels. We next tested this hypothesis experimentally. In this experiment, three 435 groups of animal treatments were applied: non-stress control treated with ESCIT (10 mg kg-1, 436 i.p.), CMS mice treated with saline then ESCIT (10 $\mathrm{mg} \mathrm{kg}^{-1}$, i.p.), and CMS mice co437 administered ESCIT (10 $\mathrm{mg} \mathrm{kg}^{-1}$, i.p.) and a histamine synthesis inhibitor (FMH, $20 \mathrm{mg} \mathrm{kg}^{-1}$, i.p.) 438 (Figure 7B).

439 Both non-stress controls and CMS-treated mice show increases in ambient serotonin following 440 ESCIT administration (confirmed with a Bland-Altman test), however post ESCIT-ambient 441 serotonin is lower in stress mice vs. controls. To simultaneously increase serotonin and 442 decrease histamine, we co-administered ESCIT and a FMH (a suicide inhibitor of histidine 443 decarboxylase) to another cohort of CMS mice. In these mice, we saw that ambient serotonin 444 increased faster and to a level comparable to a control mouse and co-administration of ESCIT 445 and FMH induced robust increases in ambient serotonin (see ANCOVA in supplemental). 446 Strikingly the experimental data (Figure 7B) is in very close agreement with the model 
447 predictions (Figure 7A). Thus, dual targeting of serotonin and histamine effectively restores

448 serotonin to control levels in stress mice (see schematic in Figure 7C).

\section{Discussion}

\section{Diminished Extracellular Serotonin Marks Chronic Stress in Mice}

451 To identify a biomarker for disease one needs a theory that implicates a chemical change within

452 the pathogenesis of the disease and a way to experimentally validate that chemical change.

453 While this process is straight-forward in many diseases of the periphery (e.g. high blood glucose

454 levels during diabetes), it is an exceptionally challenging task to define biomarkers in the brain

455 due to the complexities of chemically probing this organ [41]. Many decades of elegant work

456 have narrowed down some hypotheses of depression. The long-standing monoamine theory

457 postulates that extracellular levels of the monoamines, particularly serotonin, are lower during

458 depression (inducible by but not limited to chronic stress) [42]. Indeed, SSRIs are still the

459 frontline clinical therapy for depression, the idea being that inhibition of the serotonin

460 transporters (SERTs) will correct the presumed serotonin deficit. However there has been

461 incongruity in the community about whether brain or body levels of serotonin, or the levels of

462 serotonin metabolites, are reproducibly correlated to depressive state in animals and humans

463 [15]. Additionally, while SSRIs do bring clinical relief to many who take them, they are

464 ineffective for the majority. Because of the disagreements about serotonin as a biomarker, the

465 mode of SSRI action and the inability to better screen novel compounds [43, 44], there has

466 been a significant loss of interest in the research community in serotonin-targeting agents.

467 Serotonin's roles remain uncertain due to a lack of methods that can capture serotonin signaling

468 in the intact brain on neurotransmission spatial and temporal scales. During the past decade,

469 we have developed a unique set of voltammetric tools that can robustly characterize serotonin 470 neurochemistry in vivo. FSCV can capture evoked serotonin release and reuptake with 
471 millisecond time resolution [20] and FSCAV can measure minute to minute basal, extracellular

472 concentrations [32]. Here we apply these tools to bring clarity to the question of serotonin as a

473 biomarker of stress and stress-induced depression-like behaviors in mice. There are many

474 models of behavioral depression in animals and ongoing discussion in the field as to the validity

475 and reproducibility of these tests [23, 45-53]. Largely, there is accord that CMS [34, 54] induces

476 anxiety and depression-like phenotypes in male and female mice [54, 55], and there is evidence

477 for serotonin underpinning these responses [56-62]. It's also clear that stress plays an important

478 role in the chemical pathology of human depression [63]. In a representative cohort of mice that

479 underwent chronic mild stress, we found one or more depression-like behaviors in $41-77 \%$ of

480 the mice (depending on the behavior). It is well established that individual differences determine

481 behavioral response to stress including stress resilient subgroups [64-67]. The novel finding

482 here is that every single mouse who underwent the CMS paradigm had lower extracellular 483 levels of serotonin compared to controls.

484 We next asked whether we could mathematically predict, based on this ambient serotonin 485 measurement alone, whether animals had undergone the chronic stress paradigm. Using 1000 486 independent runs of a clustering algorithm with random shuffling of data, we observe that the 487 clustering almost $90 \%$ of the times correctly categorizes the mice population as stressed vs. 488 non-stressed. Thus, we show FSCAV measurements of ambient serotonin level are a stand489 alone marker of chronic stress and chronic stress induced depression-like behaviors in mice. 490 Just as significant were the correlations between serotonin concentration and the magnitude of 491 behavioral response, underpinning serotonin's validity as a behavioral marker. Correlations 492 between voltammetrically measured transmitter levels and behavior have previously been 493 observed [68], in the context of dopamine and learning.

494 Decreased basal serotonin levels are especially interesting given no change in the evoked 495 serotonin response. We previously described our evoked serotonin response as a function of 
serotonin synthesis, packaging, release, reuptake, and metabolism [20,69] so the unchanged

497 signal implies that none of these synaptic parameters changed. This finding clearly shows that

498 there is more to the story than serotonin (and the monoamine hypothesis) alone [14].

\section{Histamine Attenuates Extracellular Serotonin via Stress-Induced Inflammation}

500 The undeniable comorbidity between stress, inflammation and depression [70-74] has recently

501 directed the community towards the cytokine theory of depression. The notion here is that the

502 biochemical cascades accompanying immune activity and pro-inflammatory cytokine release in

503 the periphery directly influence the (monoaminergic and/or other) neurochemistry that underlies

504 depression [10]. In this context, we performed plasma cytokine analysis on the (same) CMS and

505 control mice. We found weak relationships between cytokine levels and stress and no

506 relationship between cytokines and behavior (Supplementary Figure S8). It is well chronicled

507 that CMS induces chronic inflammation, [75-77] however plasma cytokine analysis is not a

508 robust predictor of stress, nor depressive-like behaviors [16, 78-83]. It's likely because collected

509 biochemical samples (quickly metabolized/inactivated) often lose nuance and it is the real-time

510 in vivo signaling that carries the message. However, as with the monoamine theory, it is difficult

511 to measure inflammation signaling in the brain. We recently developed the technology to

512 measure histamine with voltammetry [31, 33]. We showed that measurements of evoked

513 hypothalamic histamine signify acute inflammation [40] and that this inflammation-induced

514 histamine inhibits serotonin release via inhibitory $\mathrm{H} 3$ heteroreceptors on serotonin terminals

515 [40]. Many other studies in literature further indicate that histamine strongly influences

516 extracellular serotonin levels [33, 36, 84, 85], thus we decided to focus next on brain histamine.

517 We first developed a mathematical model of a bidirectional relationship between serotonin and

518 histamine in the hypothalamus accounting for the negative modulation of serotonin by histamine

519 mediated through H3 heteroreceptors (based on our own and others' previous work) and a 520 positive modulation of histamine by serotonin (based on the status quo in the literature). The 
521 release of the two neuromodulators was modelled as two independent differential equations.

522 Extracellular histamine and serotonin concentrations were regulated by their neuronal firing 523 rates, vesicular concentrations in the releasing terminals, and reuptake mechanisms at their

524 respective terminals and surrounding glial cells, represented by respective decay time 525 constants. We chose the hypothalamus because this is the only experimental model available to 526 us to simultaneously test histamine and serotonin dynamics [33].

527 Nullcline analysis, a common analytical tool used to find the steady state of a system, allowed 528 us to postulate that increasing histamine levels are concurrent with decreasing serotonin, as 529 seen in our CMS mice and also helped to parametrize the model. Next, we voltammetrically 530 measured histamine in the hypothalamus of a second cohort of CMS mice and verified the 531 model's prediction. Histamine release was elevated in these mice compared to controls. Thus, 532 in addition to serotonin, evoked histamine marks chronic stress. These findings may synergize 533 the monoamine and cytokine theories.

534 We next dug into the nuances of this intersection and asked which parameter in the model most 535 influenced the model system. We found, using a parameter sensitivity analysis, that changes in 536 histamine were the most significant for their effects on serotonin, specifically, $\mathrm{T}_{\mathrm{H}}$, had the biggest 537 impact on the system. This is an exceptionally interesting finding since until recently, active 538 histamine transport had not been described. We and others have found evidence for active 539 histamine reuptake, most likely via the organic cation transporters (OCTs) [40, 86-89]. Even 540 more compelling is recent evidence that agents with antidepressant activity (like SSRIs) have off 541 target effects on histamine reuptake [40].

\section{$542 S_{i}$ Suggests Novel Approach to Improving Chemical Efficacy of Escitalopram via}

\section{Targeted Histamine Inhibition}

544 Depression in humans is graded using behavioral observations and questionnaires [90] and in 545 animals via an index of a depressive-like behavior [91]. Inaccuracies are innate in both these 
546 approaches due to subjectivity (humans) and irreproducibility (animals). By marrying the

547 behavioral and chemical data to our model, we next developed a novel general measure, which

548 we coin 'the stress index' $\left(\mathrm{S}_{\mathrm{i}}\right)$, in the hippocampus. Our model was built on experimental data

549 showing correlations between serotonin and behavior and serotonin/histamine modulation in the

550 hypothalamus. We are not able to measure the modulation of baseline serotonin by histamine in

551 the hippocampus (as in the hypothalamus) because the stimulation releases both serotonin and

552 histamine. Thus we combine the hippocampal ambient serotonin data (from Figure 2) with our

553 hypothalamic model (Figure 3) to estimate hippocampal histamine levels and model parameters

554 (Supplementary Figure S4A) since inhibitory H3 heteroreceptors are also found on serotonin

555 terminals in the hippocampus $[38,39]$.

556 To make sure that $S_{i}$ is robust against the exact equation used, we considered many different

557 functional dependencies for histamine and serotonin on $S_{\text {I }}$ (Supplementary Figure S2).

558 Remarkably, the system shows conserved behavior for all the different functional dependencies

559 considered. $S_{i}$ is the metric that integrates contributions from both serotonin and histamine as

560 opposed to the contributions from serotonin or histamine in isolation towards behavior.

561 Compared to existing behavioral grading of depression, $\mathrm{S}_{\mathrm{i}}$, that basis its grading on chemistry,

562 represents a significant advance in stratifying animals.

563 We independently varied the parameters associated with serotonin and histamine in the model

564 (Figure 3) and observed their effect on $S_{i}$ (Supplementary Figure S3). During stress, we found

565 that decreasing $\mathrm{T}_{\mathrm{HA}}$, corresponding to increased histamine reuptake and increasing $\mathrm{I}_{5 \mathrm{HT}}$,

566 corresponding to a surge in extracellular serotonin leads to a significant reduction in $S_{i}$ as

567 observed through the large changes from basal levels (Figure 5). Thus, $\mathrm{T}_{\mathrm{HA}}$ and $\mathrm{I}_{5 \mathrm{HT}}$ maximally

568 contribute to reducing $\mathrm{S}_{\mathrm{I}}$.

569 In both control and stress conditions, the model predicts that ESCIT administration will cause an

570 increase in $S_{i}$ (via reduction in serotonin, counter to the idea that SSRIs increase serotonin), 
571 precisely because of ESCIT's effect on histamine (as above, small changes in histamine create

572 large changes in serotonin). Theoretically SSRIs should increase serotonin levels by inhibiting

573 the serotonin transporter; indeed, we have found this to be the case for acute escitalopram

574 (ESCIT) administration to mice (Saylor 2019). The model contradicts theory and indeed

575 experiments [40]. This is because the model does not take into account the differing affinities of

576 ESCIT for inhibiting serotonin and histamine reuptake. The much higher affinity of ESCIT for

577 SERTs than OCTs explains the model's mismatch with experimental data. Nonetheless the

578 model shines an important spotlight on histamine as a means to modulate serotonin. For the

579 next question, we took into account into the varying affinities of ESCIT for serotonin and

580 histamine transporters and asked the model how best to restore stress-induced decreased

581 serotonin to pre-stress control levels. The model predicted that a dual approach, targeting both

582 serotonin and histamine would be the most effective. When we performed the equivalent

583 experiments by co-administering and SSRI and a histamine synthesis inhibitor, we almost

584 entirely replicated the model's predictions experimentally. We have, as yet to find a chronic drug

585 treatment paradigm that does not cause inflammation-induced histamine, thus we have not yet

586 tested the effects of chronic FMH administration. Nonetheless this acute experiment highlights

587 the potential importance of histamine.

\section{Conclusions}

589 In this work, we combined cutting edge experimental and mathematical tools to study the nexus

590 of the monoamine and cytokine theories of depression in a chronic stress model by focusing on

591 serotonin and histamine. We created models to stratify mice that had undergone a chronic mild

592 stress model along a scale, $S_{i}$. When $S_{i}$ was high our model predicted that a simultaneous

593 increase in serotonin and decrease in histamine would be the most effective chemical strategy 
594 to return serotonin to pre-stress levels. We experimentally performed this idea via acute 595 pharmacology and our experiments were almost perfectly in line with the model's predictions.

596 In sum, our work reveals that a co-modulatory relationship between serotonin and histamine 597 marks chronic stress in mice. While it is clear that stress and depression pathology extend 598 beyond histamine and serotonin, we suggest that it is not yet time to give up on serotonin. 599 Rather we propose that in vivo serotonin and histamine co-modulatory dynamics be considered 600 as biomarkers in future investigations of the pathology and treatment of depression.

\section{List of Abbreviations}

$6025 \mathrm{HT}-$ Serotonin

603 ANCOVA - Analysis of covariance

604 AUC - Area under the curve

605 CFMs - Carbon fiber microelectrodes

606 CMS - Chronic mild stress paradigm

607 CV - Cyclic voltammogram

608 ESCIT - Escitalopram

609 EZM - Elevated zero maze

610 FSCAV - Fast scan-controlled adsorption voltammetry

611 FSCV - Fast scan cyclic voltammetry

612 FMH - fluoromethylhistidine

613 FST - Forced swim test

$614 \quad \mathrm{HA}-$ Histamine

$615 \quad I_{5 H T}-$ Tonic supply of serotonin

$616 \mathrm{I}_{\mathrm{HA}}-$ Tonic supply of histamine

617 i.p. - Intraperitoneal injection 
618 IT - Current vs. time

619 OCTs - Organic cation transporters

620 SEM - Standard error of the mean

621 SERTs - Serotonin transporters

$622 S_{i}-$ Stress index

623 SPT - Sucrose preference test

624 SSRIs - Selective serotonin reuptake inhibitors

$625 \mathrm{~T}_{5 \mathrm{HT}}-$ Decay/reuptake time constant for serotonin

$626 \mathrm{~T}_{\mathrm{HA}}-$ Decay/reuptake time constant for histamine

627 TST - Tail suspension test

\section{Declarations}

\section{Ethics approval and consent to participate}

630 All animal procedures and protocols were performed in accordance with regulations of the 631 Institutional Animal Care and Use Committee (IACUC) at the University of South Carolina, 632 which operates with accreditation from the Association for Assessment and Accreditation of 633 Laboratory Animal Care (AAALAC).

\section{Consent for publication}

635 Not applicable

\section{Availability of data and materials}

637 The datasets used and/or analyzed during the current study are available from the 638 corresponding author on reasonable request. 
640 The authors declare that they have no competing interests.

641 Funding

642 This work was supported by the National Institutes of Health R01MH106563 (PH),

643 R21MH109959 (PH), BBSRC BB/N013956/1 (CC), BB/N019008/1 (CC), Wellcome Trust

644 200790/Z/16/Z (CC), Simons Foundation 564408 (CC), EPSRC EP/R035806/1 (CC), and

645 Department of Veterans Affairs grant numbers I21 BX002085 (LPR) and IO1 BX001804 (LPR).

\section{Authors Contributions}

647 Experiments were designed by $\mathrm{PH}$ and $\mathrm{MH}$, data was collected by $\mathrm{MH}, \mathrm{SB}, \mathrm{AMB}, \mathrm{YO}$, and $\mathrm{NT}$.

648 Mathematical models were designed by MR and CC. Statistics were performed by SM.

649 Manuscript was written by $\mathrm{MH}, \mathrm{MR}, \mathrm{CC}$, and $\mathrm{PH}$ with edits and revisions by other authors.

650 Acknowledgments

651 The authors would like to thank Rachel Saylor for setting up the behavioral suite at UofSC,

652 Eugene Jones for assistance with behavioral analysis, lan Bain for assistance with electrode

653 fabrication and histology, all other members of the Hashemi lab for assistance with mouse

654 maintenance and helpful discussions. We would also like to thank Dr. Eric Nestler (Mount Sinai)

655 for assistance and training on mouse behavioral testing.

\section{References}

657 1. Depression Fact Sheet [https://www.who.int/news-room/fact-sheets/detail/depression]

658 2. James SL, Abate D, Abate KH, Abay SM, Abbafati C, Abbasi N, Abbastabar H, Abd-Allah F, 659 Abdela J, Abdelalim A: Global, regional, and national incidence, prevalence, and years $660 \quad$ lived with disability for $\mathbf{3 5 4}$ diseases and injuries for 195 countries and territories, 1990-2017: a systematic analysis for the Global Burden of Disease Study 2017. The Lancet 2018, 392:1789-1858.

664

665

666

3. Salari N, Hosseinian-Far A, Jalali R, Vaisi-Raygani A, Rasoulpoor S, Mohammadi M, Rasoulpoor S, Khaledi-Paveh B: Prevalence of stress, anxiety, depression among the general population during the COVID-19 pandemic: a systematic review and metaanalysis. Globalization and health 2020, 16:1-11. 
667 4. Artigas F, Bortolozzi A, Celada P: Can we increase speed and efficacy of antidepressant 668 treatments? Part I: general aspects and monoamine-based strategies. European $669 \quad$ Neuropsychopharmacology 2018, 28:445-456.

670 5. Belmaker RH, Agam G: Major depressive disorder. N Engl J Med 2008, 358:55-68.

671 6. Krishnan V, Nestler EJ: The molecular neurobiology of depression. Nature 2008, 672 455:894-902.

673 7. Krystal JH, Neumeister A: Noradrenergic and serotonergic mechanisms in the

8. Chaouloff F: Physiopharmacological interactions between stress hormones and central serotonergic systems. Brain Research Reviews 1993, 18:1-32.

9. Harvey BH, Naciti C, Brand L, Stein DJ: Serotonin and stress: protective or malevolent

10. Haase J, Brown E: Integrating the monoamine, neurotrophin and cytokine hypotheses

11. Raison CL, Rutherford RE, Woolwine BJ, Shuo C, Schettler P, Drake DF, Haroon E, Miller actions in the biobehavioral response to repeated trauma? Annals of the New York Academy of Sciences 2004, 1032:267-272.

of depression-a central role for the serotonin transporter? Pharmacology \& therapeutics 2015, 147:1-11. $\mathrm{AH}$ : A randomized controlled trial of the tumor necrosis factor antagonist infliximab for treatment-resistant depression: the role of baseline inflammatory biomarkers. JAMA psychiatry 2013, 70:31-41.

12. Lee $\mathrm{Y}$, Subramaniapillai M, Brietzke E, Mansur RB, Ho RC, Yim SJ, Mclntyre RS: Anticytokine agents for anhedonia: targeting inflammation and the immune system to treat dimensional disturbances in depression. Therapeutic advances in psychopharmacology 2018, 8:337-348.

13. Bai S, Guo W, Feng Y, Deng H, Li G, Nie H, Guo G, Yu H, Ma Y, Wang J: Efficacy and safety of anti-inflammatory agents for the treatment of major depressive disorder: a systematic review and meta-analysis of randomised controlled trials. Journal of Neurology, Neurosurgery \& Psychiatry 2020, 91:21-32.

14. Hersey $M$, Hashemi $P$, Reagan LP: Integrating the Monoamine and Cytokine Hypotheses of Depression: Is histamine the missing link? European Journal of Neuroscience 2021.

15. Pech J, Forman J, Kessing LV, Knorr U: Poor evidence for putative abnormalities in cerebrospinal fluid neurotransmitters in patients with depression versus healthy nonpsychiatric individuals: A systematic review and meta-analyses of 23 studies. Journal of affective disorders 2018, 240:6-16.

16. Marques-Deak A, Neto FL, Dominguez W, Solis A, Kurcgant D, Sato F, Ross J, Prado E: Cytokine profiles in women with different subtypes of major depressive disorder. Journal of Psychiatric Research 2007, 41:152-159.

17. Steptoe A, Kunz-Ebrecht S, Owen N, Feldman PJ, Willemsen G, Kirschbaum C, Marmot $\mathrm{M}$ : Socioeconomic status and stress-related biological responses over the working day. Psychosomatic medicine 2003, 65:461-470.

18. Farooq RK, Isingrini E, Tanti A, Le Guisquet A-M, Arlicot N, Minier F, Leman S, Chalon S, Belzung C, Camus V: Is unpredictable chronic mild stress (UCMS) a reliable model to 

231:130-137.

19. Mormède C, Castanon N, Médina C, Moze E, Lestage J, Neveu PJ, Dantzer R: Chronic mild stress in mice decreases peripheral cytokine and increases central cytokine expression independently of IL-10 regulation of the cytokine network. Neuroimmunomodulation 2002, 10:359-366.

20. Hashemi P, Dankoski EC, Petrovic J, Keithley RB, Wightman RM: Voltammetric detection of 5-hydroxytryptamine release in the rat brain. Anal Chem 2009, 81:9462-9471.

21. Papp $M$, Willner $P$, Muscat $R$ : An animal model of anhedonia: attenuation of sucrose consumption and place preference conditioning by chronic unpredictable mild stress. Psychopharmacology 1991, 104:255-259.

22. Matthews K, Forbes N, Reid IC: Sucrose consumption as an hedonic measure following chronic unpredictable mild stress. Physiology \& behavior 1995, 57:241-248.

23. Forbes NF, Stewart CA, Matthews K, Reid IC: Chronic mild stress and sucrose consumption: validity as a model of depression. Physiology \& behavior 1996, 60:14811484.

24. Mineur YS, Belzung C, Crusio WE: Effects of unpredictable chronic mild stress on anxiety and depression-like behavior in mice. Behav Brain Res 2006, 175:43-50.

25. Krishnan V, Han M-H, Graham DL, Berton O, Renthal W, Russo SJ, LaPlant Q, Graham A, Lutter M, Lagace DC: Molecular adaptations underlying susceptibility and resistance to social defeat in brain reward regions. Cell 2007, 131:391-404.

26. Tucker LB, McCabe JT: Behavior of male and female C57BL/6J mice is more consistent with repeated trials in the elevated zero maze than in the elevated plus maze. Frontiers in behavioral neuroscience 2017, 11:13.

27. Yankelevitch-Yahav R, Franko M, Huly A, Doron R: The forced swim test as a model of depressive-like behavior. Journal of visualized experiments : JoVE 2015:52587.

28. Sanna MD, Ghelardini C, Thurmond RL, Masini E, Galeotti N: Behavioural phenotype of histamine $\mathrm{H} 4$ receptor knockout mice: focus on central neuronal functions. Neuropharmacology 2017, 114:48-57.

29. Franklin K: Paxinos and Franklin's The mouse brain in stereotaxic coordinates. edn. Academic Press, an imprint of Elsevier; 2013.

30. Jackson BP, Dietz SM, Wightman RM: Fast-scan cyclic voltammetry of 5hydroxytryptamine. Anal Chem 1995, 67:1115-1120.

31. Samaranayake $S$, Abdalla A, Robke R, Wood KM, Zeqja A, Hashemi P: In vivo histamine voltammetry in the mouse premammillary nucleus. Analyst 2015, 140:3759-3765.

32. Abdalla A, Atcherley CW, Pathirathna P, Samaranayake S, Qiang B, Pena E, Morgan SL, Heien ML, Hashemi P: In Vivo Ambient Serotonin Measurements at Carbon-Fiber Microelectrodes. Anal Chem 2017, 89:9703-9711.

33. Samaranayake S, Abdalla A, Robke R, Nijhout HF, Reed MC, Best J, Hashemi P: A voltammetric and mathematical analysis of histaminergic modulation of serotonin in the mouse hypothalamus. J Neurochem 2016, 138:374-383.

34. Willner P: Validity, reliability and utility of the chronic mild stress model of depression: a 10-year review and evaluation. Psychopharmacology (Berl) 1997, 134:319-329. 
35. Laitinen KS, Tuomisto L, Laitinen JT: Endogenous serotonin modulates histamine

36. Threlfell S, Cragg SJ, Kalló I, Turi GF, Coen CW, Greenfield SA: Histamine H3 receptors

44. Holtzheimer PE, Mayberg HS: Stuck in a rut: rethinking depression and its treatment. Trends in neurosciences 2011, 34:1-9.

45. Strekalova T, Steinbusch H: Factors of reproducibility of anhedonia induction in a chronic stress depression model in mice. In Mood and Anxiety Related Phenotypes in Mice. Springer; 2009: 153-176

46. Strekalova T, Steinbusch HW: Measuring behavior in mice with chronic stress depression paradigm. Progress in Neuro-Psychopharmacology and Biological Psychiatry 2010, 34:348-361.

47. Harris RB, Zhou J, Youngblood BD, Smagin GN, Ryan DH: Failure to change exploration or saccharin preference in rats exposed to chronic mild stress. Physiology \& behavior 1997, 63:91-100.

48. Sánchez C, Meier E: Behavioral profiles of SSRIs in animal models of depression, anxiety and aggression. Psychopharmacology 1997, 129:197-205.

49. Pollak DD, Rey CE, Monje FJ: Rodent models in depression research: Classical strategies and new directions. Annals of Medicine 2010, 42:252-264. 
50. Strekalova T, Couch $Y$, Kholod N, Boyks M, Malin D, Leprince P, Steinbusch HMW: Update in the methodology of the chronic stress paradigm: internal control matters. Behavioral and Brain Functions 2011, 7:9.

51. Weiss JM: Does decreased sucrose intake indicate loss of preference in CMS model? Psychopharmacology 1997, 134:368-370.

52. Cabib $S$ : What is mild in mild stress? Psychopharmacology 1997, 134:344-346.

53. Der-Avakian A, Barnes SA, Markou A, Pizzagalli DA: Translational assessment of reward and motivational deficits in psychiatric disorders. Translational Neuropsychopharmacology 2015:231-262.

54. Willner P: The chronic mild stress (CMS) model of depression: History, evaluation and usage. Neurobiology of Stress 2017, 6:78-93.

55. Willner P: Chronic mild stress (CMS) revisited: consistency and behaviouralneurobiological concordance in the effects of CMS. Neuropsychobiology 2005, 52:90110.

56. Meltzer CC, Smith G, DeKosky ST, Pollock BG, Mathis CA, Moore RY, Kupfer DJ, Reynolds $\mathrm{CF}$, 3rd: Serotonin in aging, late-life depression, and Alzheimer's disease: the emerging role of functional imaging. Neuropsychopharmacology 1998, 18:407-430.

57. Risch SC, Nemeroff CB: Neurochemical alterations of serotonergic neuronal systems in depression. The Journal of clinical psychiatry 1992.

58. Linthorst A, Flachskamm C, Holsboer F, Reul J: Local administration of recombinant human interleukin-1 beta in the rat hippocampus increases serotonergic neurotransmission, hypothalamic-pituitary-adrenocortical axis activity, and body temperature. Endocrinology 1994, 135:520-532.

59. Merali Z, Lacosta S, Anisman H: Effects of interleukin-1 $\beta$ and mild stress on alterations of norepinephrine, dopamine and serotonin neurotransmission: a regional microdialysis study. Brain research 1997, 761:225-235.

60. Broderick PA: Interleukin $1 \alpha$ alters hippocampal serotonin and norepinephrine release during open-field behavior in Sprague-Dawley animals: differences from the FawnHooded animal model of depression. Progress in Neuro-Psychopharmacology and Biological Psychiatry 2002, 26:1355-1372.

61. Rueter $L E$, Jacobs $B L: A$ microdialysis examination of serotonin release in the rat forebrain induced by behavioral/environmental manipulations. Brain research 1996, 739:57-69.

62. Griebel G: 5-Hydroxytryptamine-interacting drugs in animal models of anxiety disorders: more than 30 years of research. Pharmacology \& therapeutics 1995, 65:319395.

63. Kaul D, Schwab SG, Mechawar N, Matosin N: How stress physically re-shapes the brain: Impact on brain cell shapes, numbers and connections in psychiatric disorders. Neuroscience \& Biobehavioral Reviews 2021.

64. Southwick SM, Charney DS: The science of resilience: implications for the prevention and treatment of depression. Science 2012, 338:79-82.

65. Feder A, Nestler EJ, Charney DS: Psychobiology and molecular genetics of resilience. Nature Reviews Neuroscience 2009, 10:446-457. 
839 66. Hodes GE, Pfau ML, Leboeuf M, Golden SA, Christoffel DJ, Bregman D, Rebusi N, 840 Heshmati $\mathrm{M}$, Aleyasin $\mathrm{H}$, Warren $\mathrm{BL}$, et al: Individual differences in the peripheral immune system promote resilience versus susceptibility to social stress. Proceedings of the National Academy of Sciences 2014, 111:16136.

844

67. Han $\mathrm{M}-\mathrm{H}$, Nestler EJ: Neural substrates of depression and resilience. Neurotherapeutics 2017, 14:677-686.

68. Owesson-White CA, Cheer JF, Beyene M, Carelli RM, Wightman RM: Dynamic changes in accumbens dopamine correlate with learning during intracranial self-stimulation. Proceedings of the National Academy of Sciences 2008, 105:11957-11962.

69. Wood KM, Zeqja A, Nijhout HF, Reed MC, Best J, Hashemi P: Voltammetric and mathematical evidence for dual transport mediation of serotonin clearance in vivo. Journal of Neurochemistry 2014, 130:351-359.

70. Yirmiya R, Weidenfeld J, Pollak Y, Morag M, Morag A, Avitsur R, Barak O, Reichenberg A, Cohen E, Shavit Y: Cytokines, "depression due to a general medical condition," and antidepressant drugs. In Cytokines, stress, and depression. Springer; 1999: 283-316

71. Raison $\mathrm{CL}$, Capuron L, Miller $\mathrm{AH}$ : Cytokines sing the blues: inflammation and the pathogenesis of depression. Trends Immunol 2006, 27:24-31.

72. Dantzer R, O'Connor JC, Freund GG, Johnson RW, Kelley KW: From inflammation to sickness and depression: when the immune system subjugates the brain. Nat Rev Neurosci 2008, 9:46-56.

73. Maes M, Yirmyia R, Noraberg J, Brene S, Hibbeln J, Perini G, Kubera M, Bob P, Lerer B, Maj M: The inflammatory \& neurodegenerative (I\&ND) hypothesis of depression: leads for future research and new drug developments in depression. Metab Brain Dis 2009, 24:27-53.

74. Miller AH, Maletic V, Raison CL: Inflammation and its discontents: the role of cytokines in the pathophysiology of major depression. Biol Psychiatry 2009, 65:732-741.

75. Liu YN, Peng YL, Liu L, Wu TY, Zhang Y, Lian YJ, Yang YY, Kelley KW, Jiang CL, Wang YX: TNFalpha mediates stress-induced depression by upregulating indoleamine 2,3dioxygenase in a mouse model of unpredictable chronic mild stress. Eur Cytokine Netw 2015, 26:15-25.

76. Lu Y, Ho CS, Liu X, Chua AN, Wang W, Mclntyre RS, Ho RC: Chronic administration of fluoxetine and pro-inflammatory cytokine change in a rat model of depression. PLOS One 2017, 12:e0186700.

77. Wang YL, Han QQ, Gong WQ, Pan DH, Wang LZ, Hu W, Yang M, Li B, Yu J, Liu Q: Microglial activation mediates chronic mild stress-induced depressive- and anxietylike behavior in adult rats. J Neuroinflammation 2018, 15:21.

78. Steptoe A, Kunz-Ebrecht S, Owen N: Lack of association between depressive symptoms and markers of immune and vascular inflammation in middle-aged men and women. Psychological medicine 2003, 33:667.

79. Brambilla F, Maggioni M: Blood levels of cytokines in elderly patients with major depressive disorder. Acta Psychiatrica Scandinavica 1998, 97:309-313.

80. Himmerich H, Patsalos O, Lichtblau N, Ibrahim MA, Dalton B: Cytokine research in depression: principles, challenges, and open questions. Frontiers in Psychiatry 2019, 10:30. 
81. Müller N, Myint A-M, Schwarz MJ: Inflammatory biomarkers and depression. Neurotoxicity research 2011, 19:308-318.

82. Schmidt HD, Shelton RC, Duman RS: Functional biomarkers of depression: diagnosis, treatment, and pathophysiology. Neuropsychopharmacology 2011, 36:2375.

83. Fernandes BS, Williams LM, Steiner J, Leboyer M, Carvalho AF, Berk M: The new field of 'precision psychiatry'. BMC medicine 2017, 15:1-7.

84. Schlicker $E$, Betz $R$, Gothert M: Histamine $\mathbf{H 3}$ receptor-mediated inhibition of serotonin release in the rat brain cortex. Naunyn Schmiedebergs Arch Pharmacol 1988, 337:588590.

85. Fink K, Schlicker E, Neise A, Göthert M: Involvement of presynaptic $\mathbf{H} \mathbf{3}$ receptors in the inhibitory effect of histamine on serotonin release in the rat brain cortex. NaunynSchmiedeberg's archives of pharmacology 1990, 342:513-519.

86. Amphoux A, Vialou V, Drescher E, Brüss M, La Cour CM, Rochat C, Millan MJ, Giros B, Bönisch $\mathrm{H}$, Gautron S: Differential pharmacological in vitro properties of organic cation transporters and regional distribution in rat brain. Neuropharmacology 2006, 50:941952.

87. Gasser PJ, Lowry CA, Orchinik M: Corticosterone-sensitive monoamine transport in the rat dorsomedial hypothalamus: potential role for organic cation transporter $\mathbf{3}$ in stress-induced modulation of monoaminergic neurotransmission. Journal of Neuroscience 2006, 26:8758-8766.

88. Baganz NL, Horton RE, Calderon AS, Owens WA, Munn JL, Watts LT, Koldzic-Zivanovic N, Jeske NA, Koek W, Toney GM: Organic cation transporter 3: Keeping the brake on extracellular serotonin in serotonin-transporter-deficient mice. Proceedings of the National Academy of Sciences 2008, 105:18976-18981.

89. Horton RE, Apple DM, Owens WA, Baganz NL, Cano S, Mitchell NC, Vitela M, Gould GG, Koek W, Daws LC: Decynium-22 enhances SSRI-induced antidepressant-like effects in mice: uncovering novel targets to treat depression. Journal of Neuroscience 2013, 33:10534-10543.

90. Smarr KL, Keefer AL: Measures of depression and depressive symptoms: Beck depression Inventory-II (BDI-II), center for epidemiologic studies depression scale (CES-D), geriatric depression scale (GDS), hospital anxiety and depression scale (HADS), and patient health Questionnaire-9 (PHQ-9). Arthritis care \& research 2011, 63:S454-S466.

91. Krishnan V, Nestler EJ: Animal models of depression: molecular perspectives. Molecular and functional models in neuropsychiatry 2011:121-147. 


\section{Figures}

921 Figure 1: Behavioral changes following CMS. (A) A schematic is shown for the 16-week CMS paradigm and the behavior studies

922 that followed. (B) Average sucrose preference (sucrose water consumed - water consumed / total water consumed) in the SPT for

923 non-stress control (blue; $n=40$ ) and CMS (gray; $n=39$ ) mice. (C) Average time spent in the closed sections of the EZM is shown

924 for control (blue; $n=37$ ) and CMS (gray; $n=36$ ) mice (males and females were pooled). (D) Average percentage of time immobile

925 in the FST for male (blue) and female (light blue) control mice and male (gray) and female (light gray) CMS mice. (E) Average

926 percentage of time immobile in the TST is shown for control (blue) and CMS (gray) mice. Statistical significance $(p<0.05)$ is marked

927 by an asterisk.

928 Figure 2: Decreased extracellular serotonin marks chronic stress. (A,C) Example color plots from control and CMS mice respectively. (B,D) Example cyclic voltammograms from control and CMS mice respectively. (E) Evoked hippocampal serotonin concentration with time in control (blue) and CMS (gray) mice. (F) Example basal serotonin color plot. (G) Example basal serotonin cyclic voltammogram from which basal serotonin was calculated inset equation $(\mathrm{t}=$ Surface Concentration, $\mathrm{Q}=\mathrm{Charge}, \mathrm{n}=\mathrm{Charge}$ on the Molecule, F = Faraday Constant, and A = Surface Area). (H) Average basal serotonin in control (blue) and CMS (gray) mice are shown as bars and individual animals are denoted by circles. Error is shown as SEM and an asterisk denotes significance via student's t-test $(\mathrm{p}<0.05)$. (I) K-means clustering using extracellular serotonin to predict chronic stress $(\mathrm{k}=2)$. Mice are clustered, based on basal hippocampal serotonin levels, into depressed and control. $80 \%$ data is used for training and $20 \%$ data is used for testing. (J) Serotonin concentration and immobility in the FST, active time in the TST, sucrose preference at $1 \mathrm{hr}$, and time spent in the closed arms of the EZM. R = Pearson's Correlation Coefficient.

Figure 3: Dynamical interaction between histamine and serotonin with chronic stress. (A) Analysis of cytokine ratios (TNF-a/IL-4 and IL-6/LL4 respectively). Significance was defined as $p<0.05$ in a student's t-test. (B) A 940 schematic showing histaminergic regulation of serotonin via $\mathrm{H} 3$ heteroreceptors. (C) Schematic diagram and equations depicting the data-based possible interaction between histamine (HA) and serotonin (5HT), involved in

942 stress-induced depression. (D) Nullcline plots of serotonin and histamine are obtained for the basal level of $\mathrm{I}_{5 \mathrm{HT}}$ and

943 different levels of $\mathrm{I}_{\text {HA. }}$. The intersection points of the curves are the global equilibrium points of the system. (E)

944 Experimental data (solid magenta circles) are obtained from Samaranayake et al. 2016. The theoretical data (solid 945 black circles) have been procured from the nullcline analysis $\left(r^{2}=0.93\right)$. (F) An example color plot of histamine FSCV 946 in the hypothalamus. Oxidation of HA can be observed at $0.2 \mathrm{~V}$ (green event). Stimulation is marked by a purple box 947 at 5-7s. Averaged evoked hippocampal HA release for control (orange; $n=6$ ) and CMS-treated mice $(r e d ; n=5)$ is 948 shown.

949 Figure 4: Histamine reuptake is most crucial for regulating stress-induced depression. Two states of the 950 system have been studied (A-C) healthy, control condition associated with basal value of $\mathrm{I}_{\mathrm{HA}}=1250 \mathrm{nMs}^{-1}$ and (B-D) 
951 stressed condition associated with $\mathrm{I}_{\mathrm{HA}}=2 * 10^{4} \mathrm{nMs}^{-1}$. The serotonin levels are shown in blue bars and the associated

952 histamine levels in orange bars. (A-B) Percentage change obtained in the system's state under parameter variation is 953 shown with respect to the system's state at basal values of the respective parameters. (C-D) Local sensitivity analysis

954 has been performed to identify the parameters towards which the system is most sensitive and vulnerable. Relative 955 sensitivity signifies the vulnerability of a variable towards parameter changes, regardless of the order of the 956 magnitude of the variable as well as the parameter. The basal values of these parameters around which this analysis is performed are $\tau_{\mathrm{HA}}=0.8 \mathrm{~s}^{-1}, \tau_{5 \mathrm{HT}}=0.8 \mathrm{~s}^{-1}, \alpha=69.7961 \mathrm{~s}^{-1}, \beta=0.0013 \mathrm{~s}^{-1}, \mathrm{I}_{5 \mathrm{HT}}=56.3250 \mathrm{nMs}^{-1}$ and $\mathrm{I}_{\mathrm{HA}}=1250 \mathrm{nMs}^{-1}$

958 for the healthy condition and $\mathrm{I}_{\mathrm{HA}}=2 * 10^{4} \mathrm{nMs}^{-1}$ for the stressed condition

959 Figure 5: Histamine reuptake critically shapes Stress Index $\left(S_{i}\right)$. $(A)$ This equation describes $S_{i}$. The first term is a 960 heaviside function that acts as a switch filtering the state of the system as either control or depressed based on the 961 histamine concentration. A value of zero is ascribed to this term when the histamine concentration exceeds the basal histamine level. Further, the second term describes the impact histamine levels above the basal histamine value has on $S_{i}$. which is a linear rise. The last term describes the contribution of serotonin towards Si which either alleviates or exacerbates stress-induced depression in an exponential manner. (B) A schematic illustration of the metric $S_{i}$. $S_{i}$ is a positive scalar function that grades stress based on histamine and serotonin steady-state levels. A $S_{i}$ value of zero corresponds to controls and an increasing value of $S_{i}$ is associated with higher stress. In this model, $S_{i}$ associated with the maximum $\mathrm{I}_{\mathrm{HA}}=2{ }^{*} 10^{4} \mathrm{nMs}^{-1}$ corresponds to a high level of stress. Further, the normal condition with $\mathrm{I}_{\mathrm{HA}}=$ $1250 \mathrm{nMs}^{-1}$ corresponds to basal or lower histamine levels and the stressed condition is associated with heightened histamine levels and significant reduction in serotonin levels. (C, D) Variation in $S_{i}$ under a two-fold increase and decrease in the parameter of interest while keeping rest of the parameters fixed. Dark red (magenta) bars refer to a two-fold increase (decrease) in the parameter. The blue bar refers to $S_{i}$ for the basal condition i.e. when all the

973 basal values of the parameters, shown here in blue bar. It may also be noticed that spanning a parameter range 974 doesn't cause a significant change in $S_{i}$. (D) The $S_{i}$ values for the stressed condition are also shown. The basal values of the various parameters are $\tau_{\mathrm{HA}}=0.8 \mathrm{~s}^{-1}, \tau_{5 \mathrm{HT}}=0.8 \mathrm{~s}^{-1}, \alpha=69.7961 \mathrm{~s}^{-1}, \beta=0.0013 \mathrm{~s}^{-1}, \mathrm{I}_{5 \mathrm{HT}}=56.3250 \mathrm{nMs}^{-1}$

976 and $\mathrm{I}_{\mathrm{HA}}=1250 \mathrm{nMs}^{-1}$ for the healthy condition and $\mathrm{I}_{\mathrm{HA}}=2^{*} 10^{4} \mathrm{nMs}^{-1}$ for the stressed condition are obtained by fitting 977 the model to the experimental data. Variation in histamine reuptake rate $\mathrm{THA}_{\mathrm{HA}}$ causes the most significant change in $\mathrm{S}_{\mathrm{i}}$.

978 Figure 6: Administration of SSRIs elevates Stress Index. (A) SSRIs not only cause an increase in serotonin by 979 blocking serotonin reuptake (the known convention) but also block histamine reuptake leading to a concomitant increase in histamine. This impact is realized in the present model through simultaneous increase in equilibrium 
histamine and serotonin levels reuptake rates, $\mathrm{THA}_{\mathrm{HA}}$ and $\mathrm{T}_{5 \mathrm{HT}}$, respectively under (A) control, (B) stress, (C) ESCIT

982 administration conditions. The stress intervention condition is associated with a two-fold decrease in tonic histamine

983 supply, IHA which may be achieved through a histamine reducing drug. The white solid circle refers to $S_{i}$ for basal

984 parameter values. The graded-color bar denotes the increase in stress index (from blue to red) due to changes in

985 histamine and serotonin concentration. It is observed that blocking histamine leads to a reduced $S_{i}$ in (C). Here, $\tau_{H A}$

$986=0.8 \mathrm{~s}^{-1}, \tau_{5 \mathrm{HT}}=0.8 \mathrm{~s}^{-1}, \alpha=398 \mathrm{~s}^{-1}, \beta=0.0013 \mathrm{~s}^{-1}, \mathrm{I}_{5 \mathrm{HT}}=118.75 \mathrm{nMs}^{-1} \cdot \mathrm{I}_{\mathrm{HA}}=1.25^{\star} 10^{4} \mathrm{nMs}^{-1}$ is considered for control

987 condition $(A), I_{H A}=3.88^{*} 10^{4} \mathrm{nMs}^{-1}$ for the stressed condition $(B)$, and $I_{H A}=1.94^{*} 10^{4} \mathrm{nMs}^{-1}$ for the stress intervention 988 condition (C).

989 Figure 7: Pharmacologically targeting hippocampal histamine and serotonin concentrations to alleviate

990 stress-induced changes in serotonin. (A) In the model, three representative mice population are considered:

991 control mice administered the SSRI escitalopram (ESCIT) (in blue), a serotonin elevating drug, chronic mild stress

992 (CMS) mice given ESCIT (in gray) and CMS mice treated with ESCIT and histamine-synthesis blockers a-

993 fluoromethylhistidine (FMH) (in purple). These representative mice population differ from one another based on their

994 serotonin levels and treatment received. It must be noted that our model has been studied at steady state. The time

995 plotted here is just to show a more realistic comparison of our model predictions with the experiments conducted to

996 test our observations. In the model ESCIT administration refers to a two-fold increase in $\mathrm{T}_{5 \mathrm{HT}}$ and 1.25 -fold increase

997 in $\mathrm{T}_{\mathrm{HA}}$. Further, FMH administration refers to a two-fold decrease in $\mathrm{I}_{\mathrm{HA}}$. Here, $\tau_{\mathrm{HA}}=0.8 \mathrm{~s}^{-1}, \tau_{5 \mathrm{HT}}=0.8 \mathrm{~s}^{-1}, \alpha=398 \mathrm{~s}^{-1}$,

$998 \beta=0.0013 \mathrm{~s}^{-1}, \mathrm{I}_{5 \mathrm{HT}}=118.75 \mathrm{nMs}^{-1}$ and $\mathrm{I}_{\mathrm{HA}}=1.25^{\star} 10^{4} \mathrm{nMs}^{-1}$ for healthy condition and $\mathrm{I}_{\mathrm{HA}}=3.88^{*} 10^{4} \mathrm{nMs}^{-1}$ for the

999 stressed condition. (B) In vivo data showing basal hippocampal serotonin in control mice given saline and then

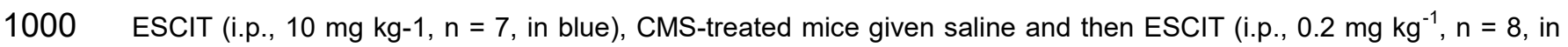

1001 gray), and CMS-treated mice given saline and then ESCIT (i.p., $10 \mathrm{mg} \mathrm{kg}^{-1}$ ) and FMH (i.p., $20 \mathrm{mg} \mathrm{kg}^{-1}, \mathrm{n}=5$, in

1002 purple). (C) Modified histamine/serotonin schematic showing the influence of an SSRI on the system in control and

1003 chronic stress. 


\section{Figures}

A

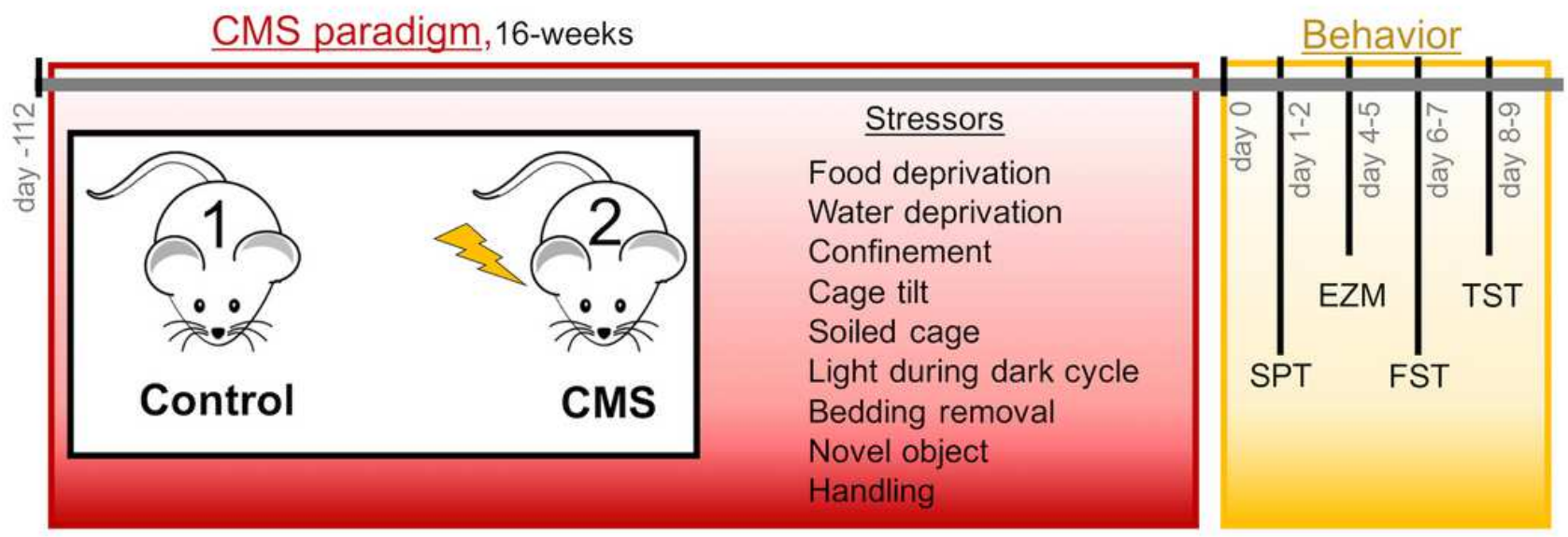

B

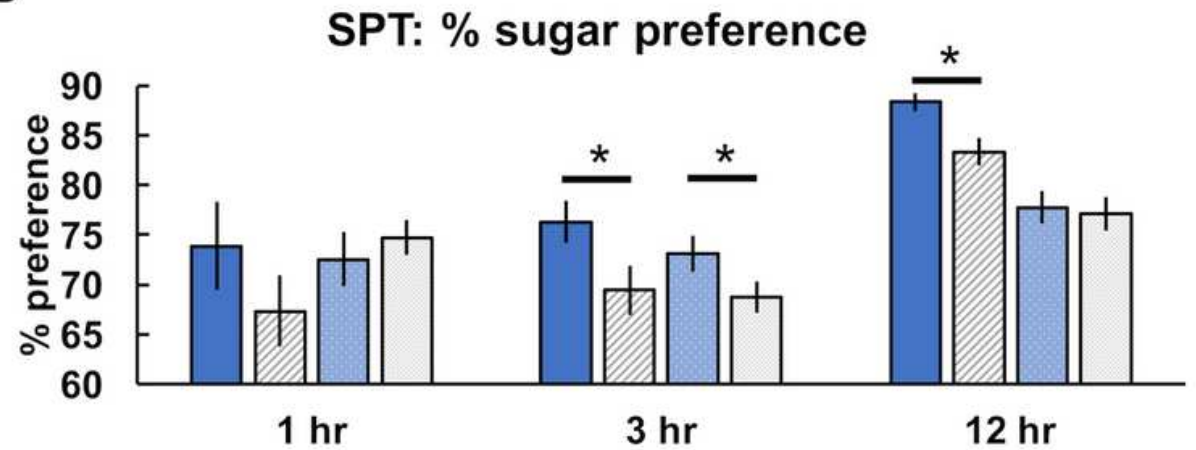

D
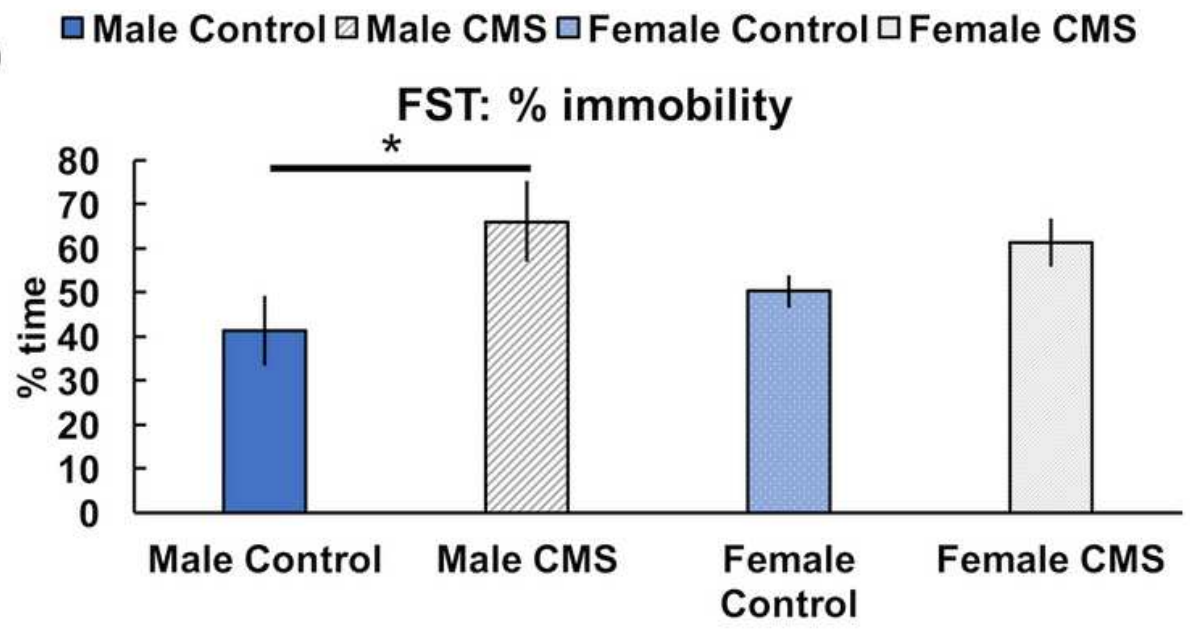

C

EZM: closed area time

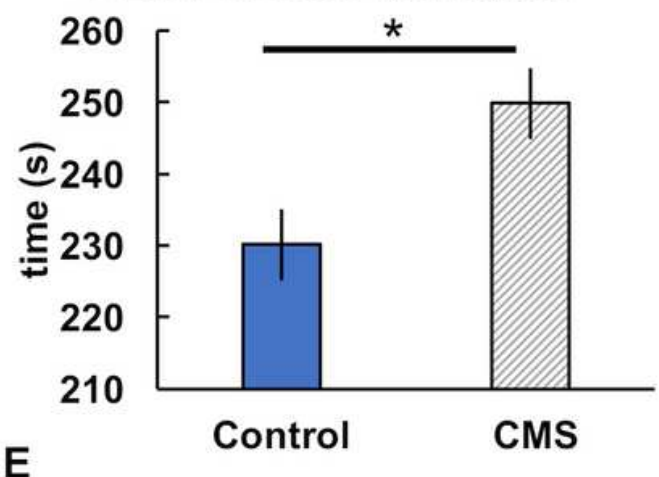

E

TST: \% immobility

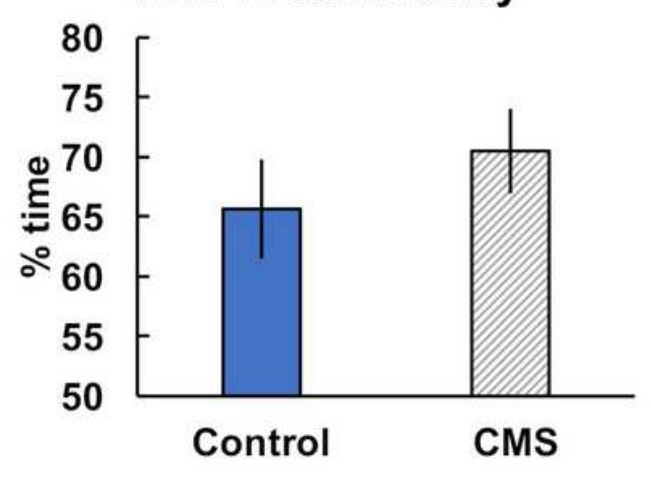

Figure 1

Behavioral changes following CMS. (A) A schematic is shown for the 16-week CMS paradigm and the behavior studies that followed. (B) Average sucrose preference (sucrose water consumed - water consumed / total water consumed) in the SPT for non-stress control (blue; $n=40$ ) and CMS (gray; $n=39$ ) mice. (C) Average time spent in the closed sections of the EZM is shown for control (blue; $n=37$ ) and CMS (gray; $n=36$ ) mice (males and females were pooled). (D) Average percentage of time immobile in the FST for male (blue) and female (light blue) control mice and male (gray) and female (light gray) CMS 
mice. (E) Average percentage of time immobile in the TST is shown for control (blue) and CMS (gray) mice. Statistical significance $(p<0.05)$ is marked by an asterisk.

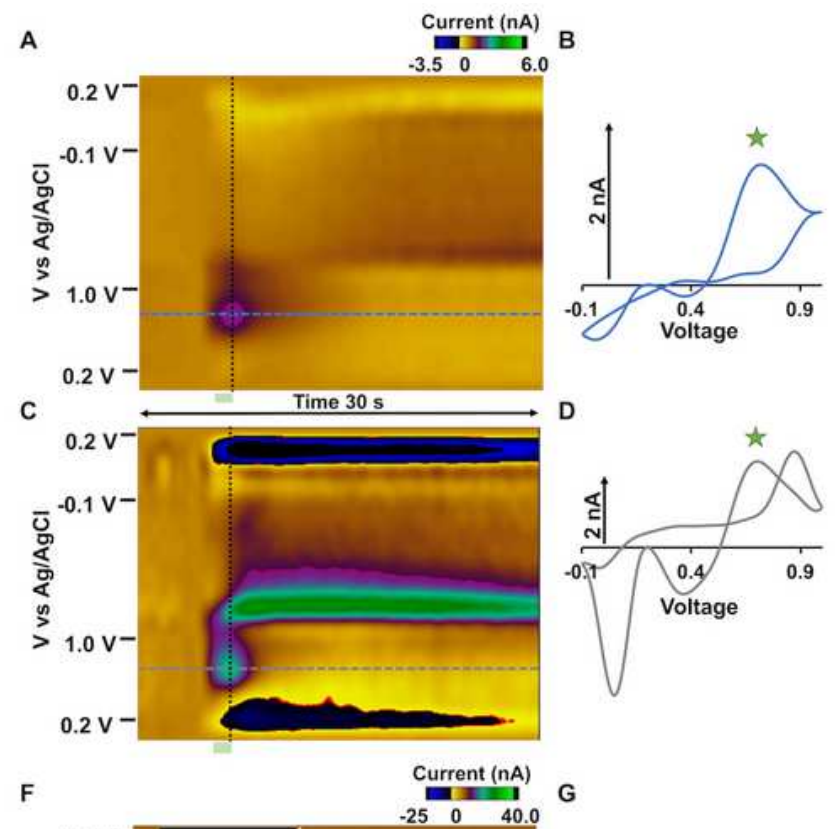

E

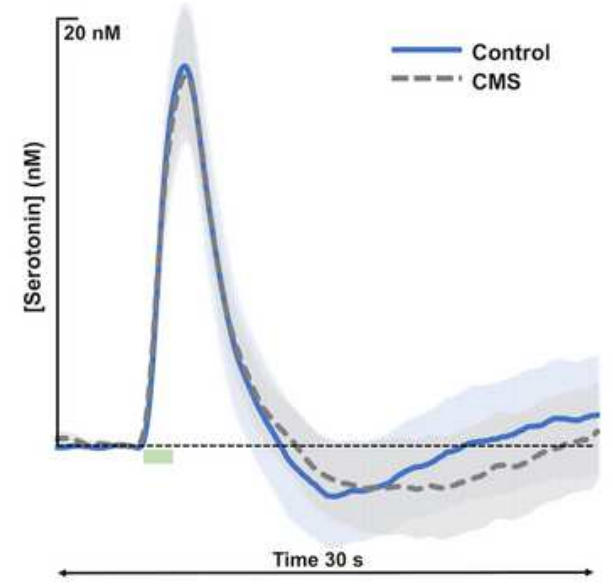

H
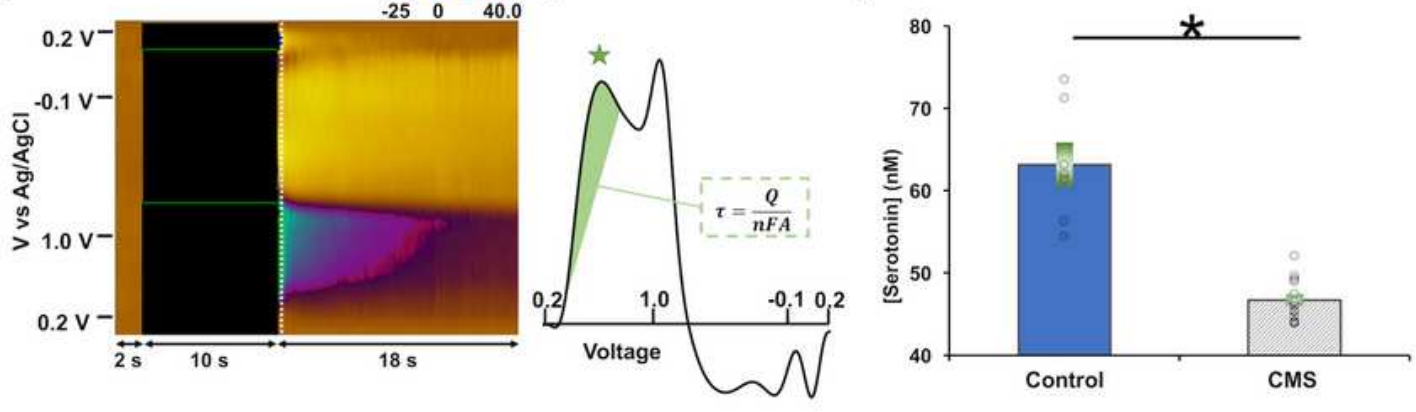

I
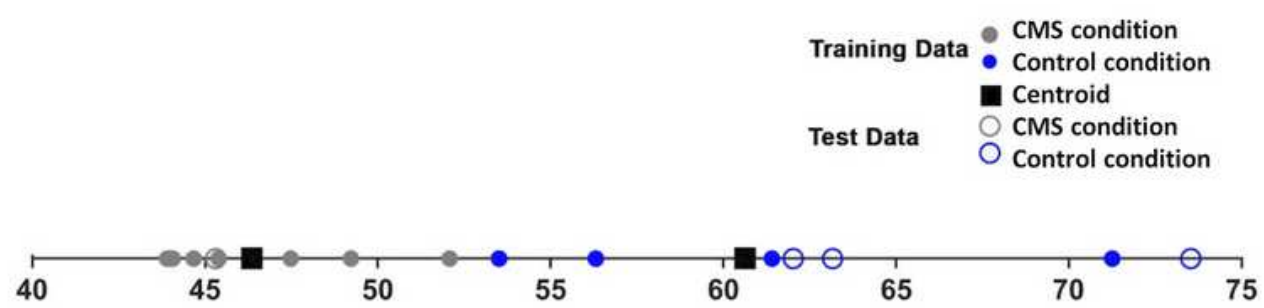

[Serotonin] (nM)

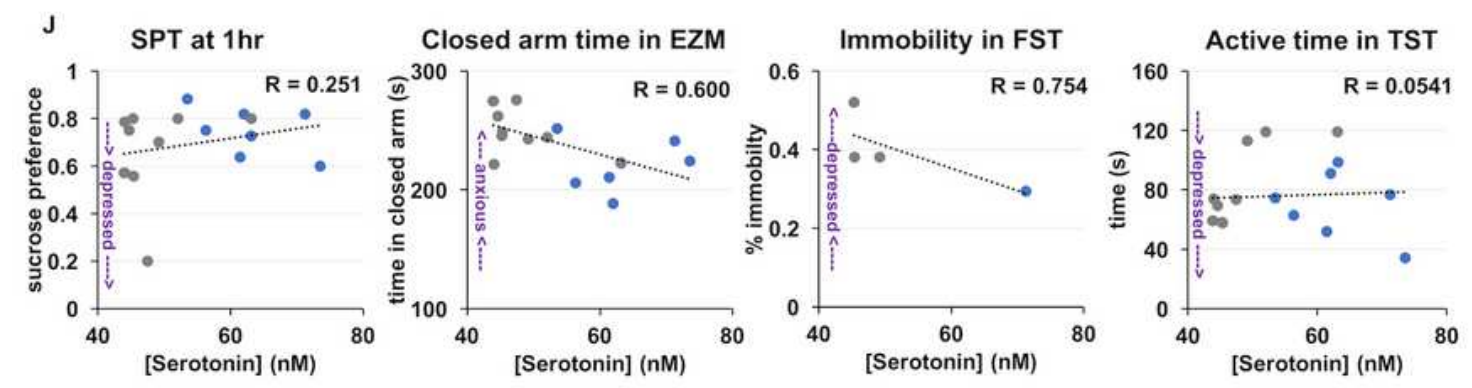

Figure 2

Decreased extracellular serotonin marks chronic stress. (A,C) Example color plots from control and CMS mice respectively. $(\mathrm{B}, \mathrm{D})$ Example cyclic voltammograms from control and CMS mice respectively. (E) Evoked hippocampal serotonin concentration with time in control (blue) and CMS (gray) mice. (F) 
Example basal serotonin color plot. (G) Example basal serotonin cyclic voltammogram from which basal serotonin was calculated inset equation ( $\tau$ = Surface Concentration, $Q=$ Charge, $n=$ Charge on the Molecule, $F=$ Faraday Constant, and A = Surface Area). $(\mathrm{H})$ Average basal serotonin in control (blue) and CMS (gray) mice are shown as bars and individual animals are denoted by circles. Error is shown as SEM and an asterisk denotes significance via student's t-test $(\mathrm{p}<0.05)$. (I) K-means clustering using extracellular serotonin to predict chronic stress $(k=2)$. Mice are clustered, based on basal hippocampal serotonin levels, into depressed and control. $80 \%$ data is used for training and $20 \%$ data is used for testing. $(J)$ Serotonin concentration and immobility in the FST, active time in the TST, sucrose preference at $1 \mathrm{hr}$, and time spent in the closed arms of the EZM. R = Pearson's Correlation Coefficient.

A

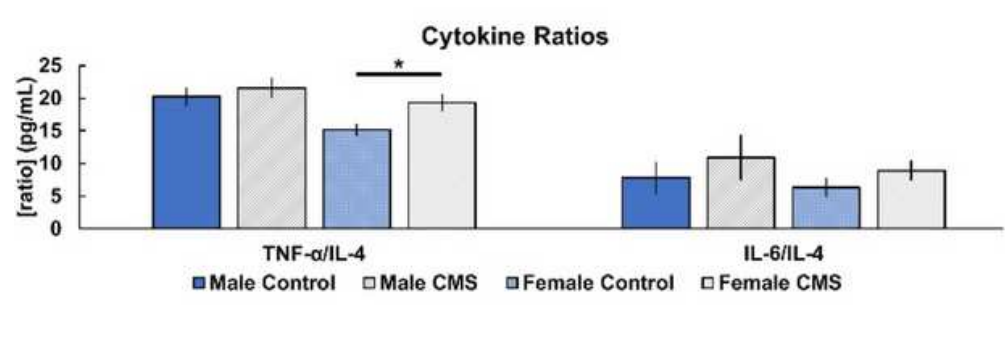

C
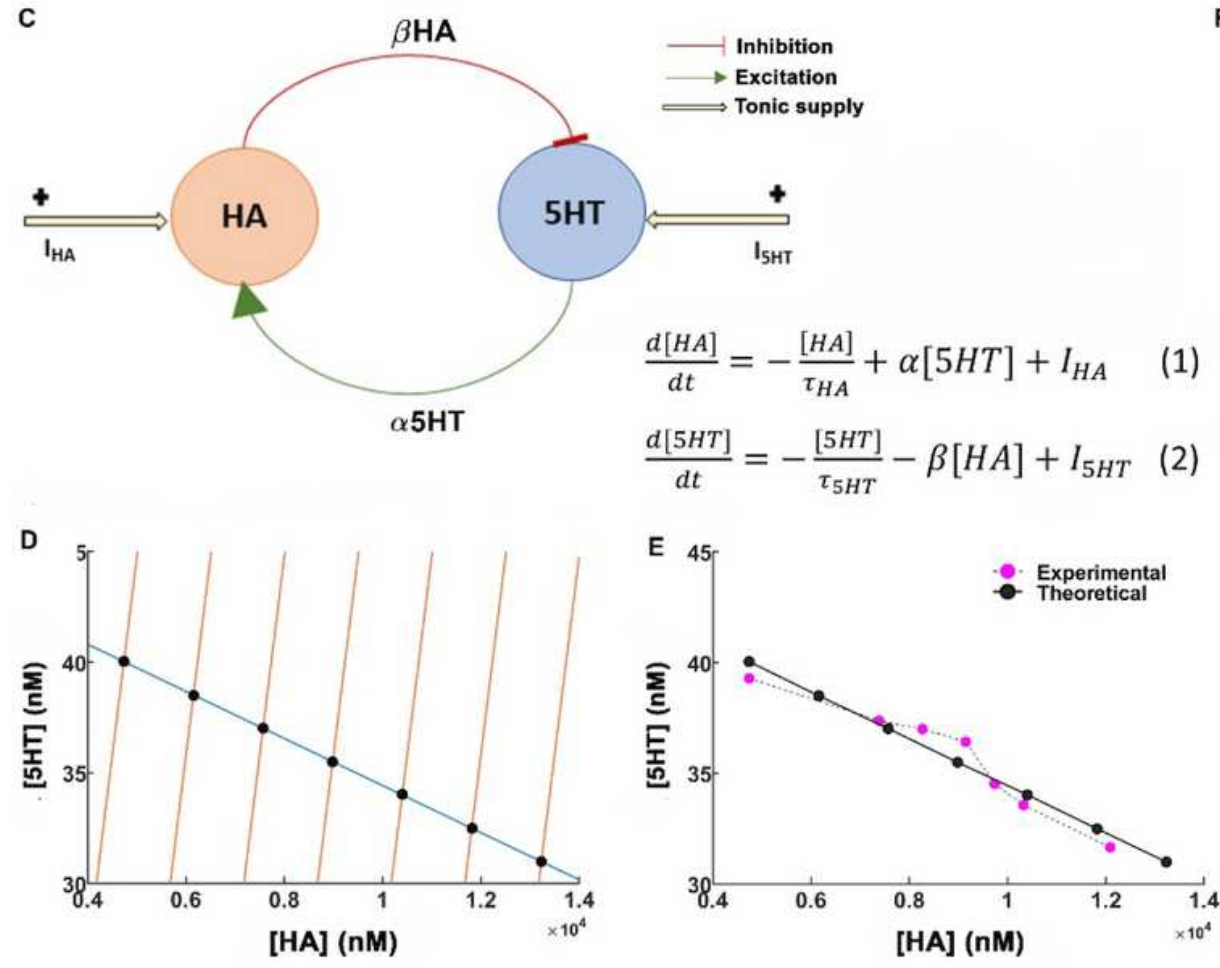

B

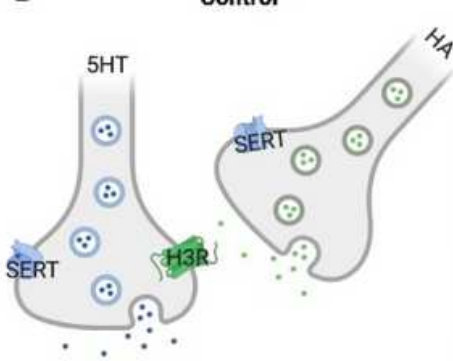

$\mathbf{F}$

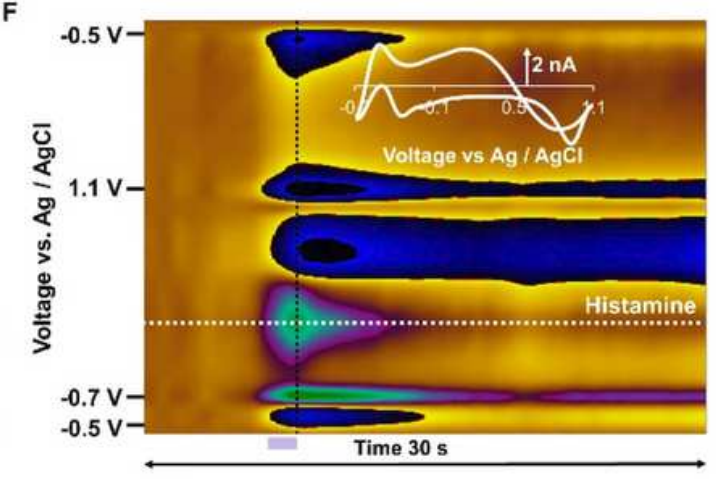

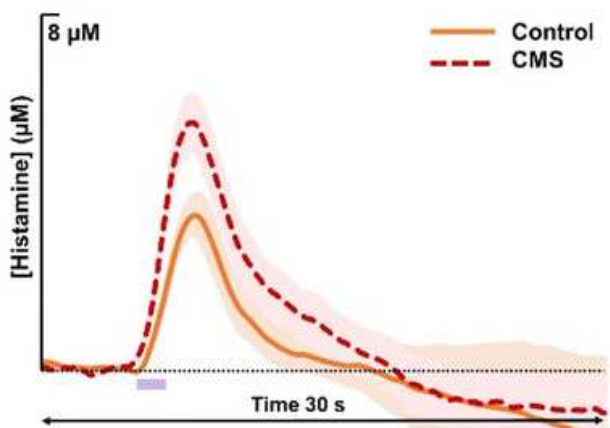

\section{Figure 3}

Dynamical interaction between histamine and serotonin with chronic stress. (A) Analysis of cytokine ratios (TNF-a/IL-4 and IL-6/IL4 respectively). Significance was defined as $p<0.05$ in a student's t-test. (B) A schematic showing histaminergic regulation of serotonin via $\mathrm{H} 3$ heteroreceptors. (C) Schematic diagram and equations depicting the data-based possible interaction between histamine (HA) and serotonin (5HT), involved in stress-induced depression. (D) Nullcline plots of serotonin and histamine are 
obtained for the basal level of I5HT and different levels of IHA. The intersection points of the curves are the global equilibrium points of the system. (E) Experimental data (solid magenta circles) are obtained from Samaranayake et al. 2016. The theoretical data (solid black circles) have been procured from the nullcline analysis $(\mathrm{r} 2=0.93)$. $(\mathrm{F})$ An example color plot of histamine FSCV in the hypothalamus.

Oxidation of $\mathrm{HA}$ can be observed at $0.2 \mathrm{~V}$ (green event). Stimulation is marked by a purple box at $5-7 \mathrm{~s}$. Averaged evoked hippocampal HA release for control (orange; $n=6)$ and CMS-treated mice $(r e d ; n=5)$ is shown.

\section{Control}

A

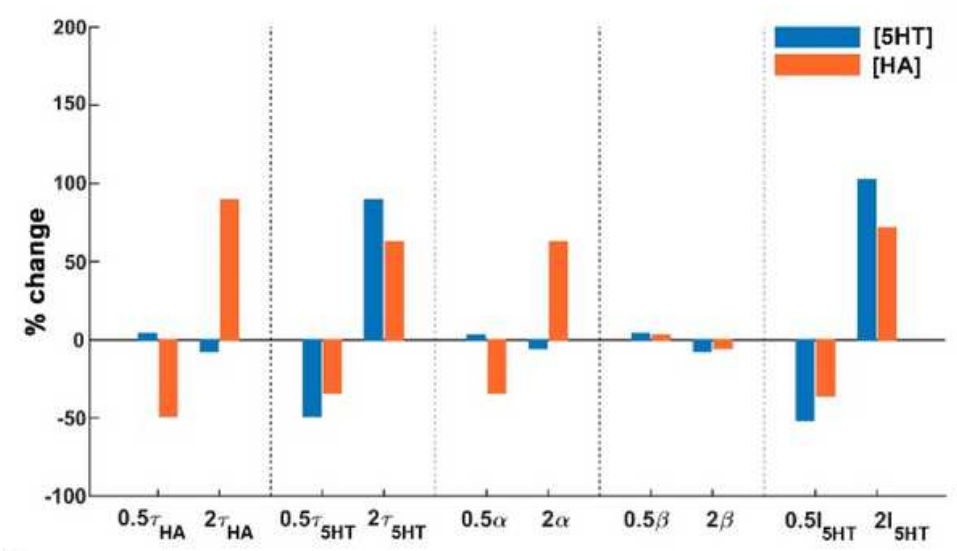

C

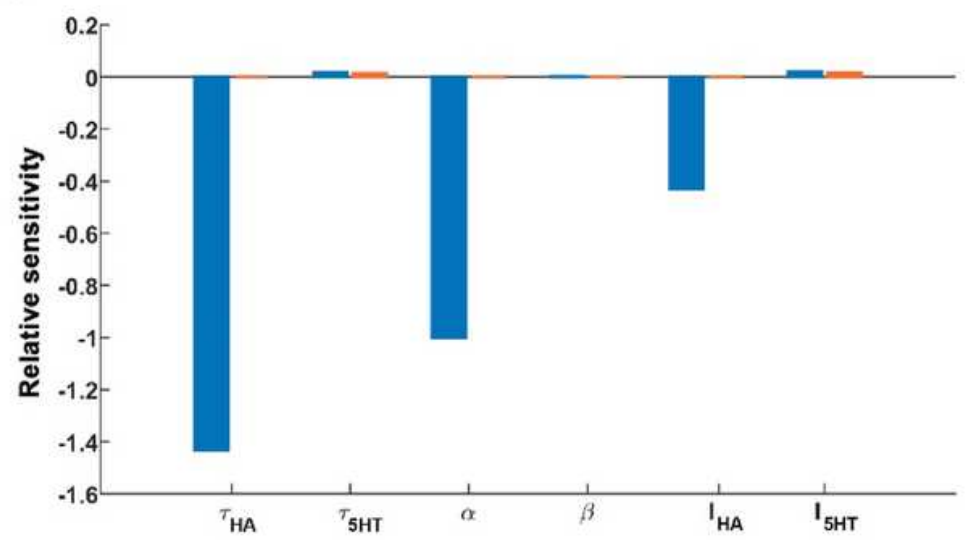

\section{Stressed}

\section{B}

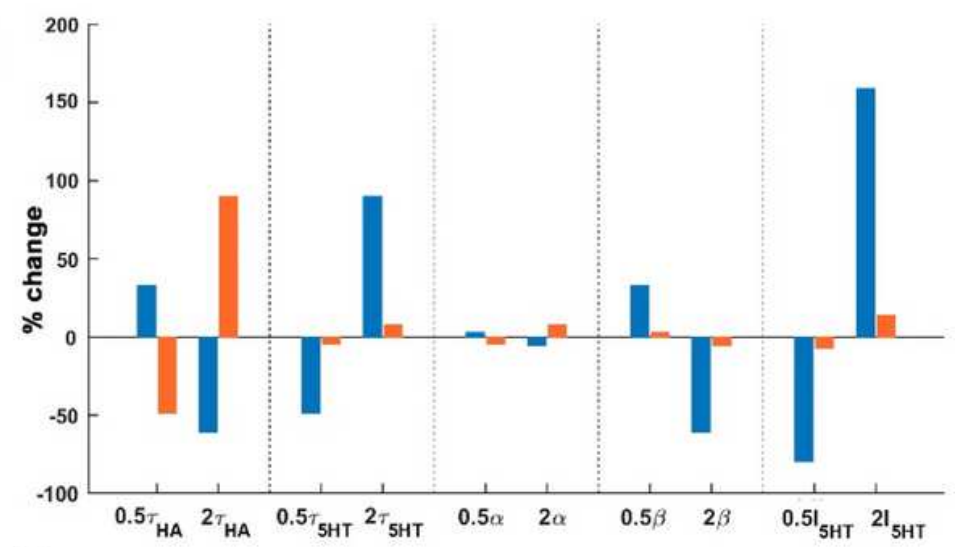

D

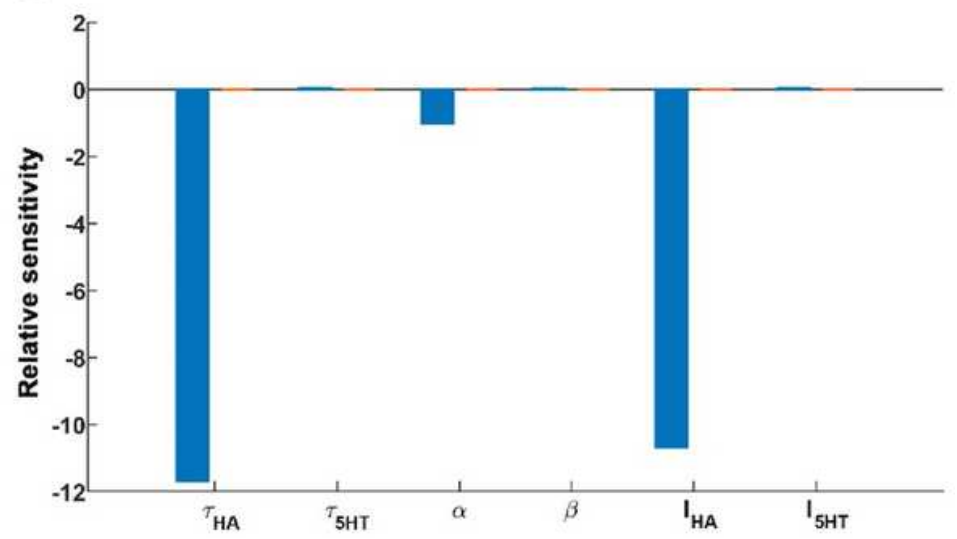

\section{Figure 4}

Histamine reuptake is most crucial for regulating stress-induced depression. Two states of the system have been studied (A-C) healthy, control condition associated with basal value of IHA $=1250 \mathrm{nMs}-1$ and (B-D) stressed condition associated with IHA $=2 * 104 \mathrm{nMs}-1$. The serotonin levels are shown in blue bars and the associated histamine levels in orange bars. (A-B) Percentage change obtained in the system's state under parameter variation is shown with respect to the system's state at basal values of the respective parameters. (C-D) Local sensitivity analysis has been performed to identify the parameters towards which the system is most sensitive and vulnerable. Relative sensitivity signifies the vulnerability of a variable towards parameter changes, regardless of the order of the magnitude of the variable as well as the parameter. The basal values of these parameters around which this analysis is performed are tHA 
$=0.8 s-1, \tau 5 H T=0.8 s-1, a=69.7961 s-1, \beta=0.0013 s-1, I 5 H T=56.3250 n M s-1$ and IHA = 1250 nMs-1 for the healthy condition and IHA $=2 * 104 \mathrm{nMs}-1$ for the stressed condition

A

$$
S_{i}=\theta\left(\frac{[H A]-[H A]_{b}}{[H A]_{b}}\right)\left(\frac{[H A]-[H A]_{b}}{[H A]_{b}}\right) e^{-\gamma\left(\frac{[5 H T]-[5 H T]_{b}}{[5 H T]_{b}}\right)}
$$

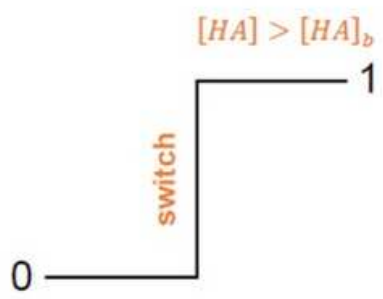

$[H A] \leq[H A]_{b}$

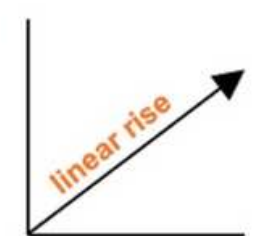

$[H A]>[H A]_{b}$

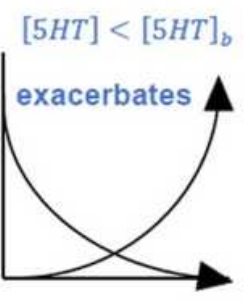

$[5 H T]>[5 H T]_{b}$ alleviates stress
B

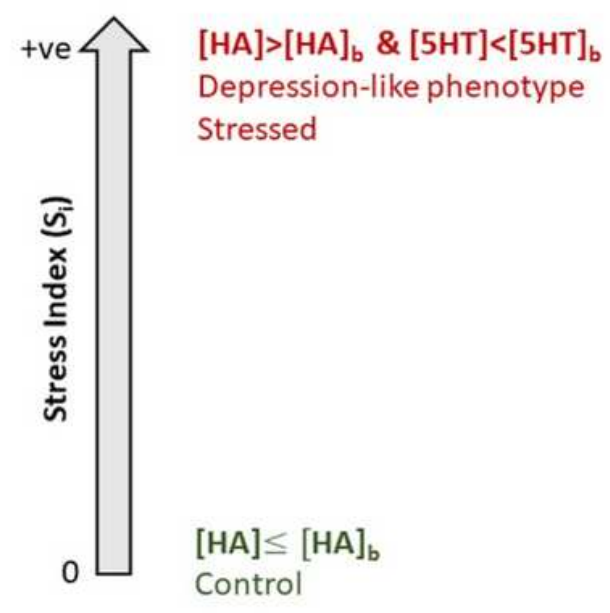

D

Stressed

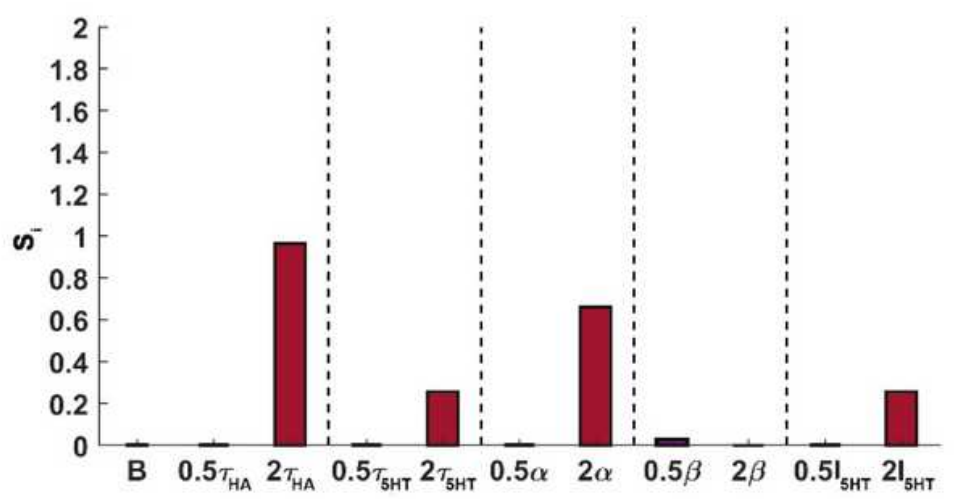

\section{Figure 5}

Histamine reuptake critically shapes Stress Index (Si). (A) This equation describes Si. The first term is a heaviside function that acts as a switch filtering the state of the system as either control or depressed based on the histamine concentration. A value of zero is ascribed to this term when the histamine concentration exceeds the basal histamine level. Further, the second term describes the impact histamine levels above the basal histamine value has on Si. which is a linear rise. The last term describes the contribution of serotonin towards Si which either alleviates or exacerbates stress-induced depression in an exponential manner. (B) A schematic illustration of the metric Si. Si is a positive scalar function that grades stress based on histamine and serotonin steady-state levels. A Si value of zero corresponds to controls and an increasing value of $\mathrm{Si}$ is associated with higher stress. In this model, Si associated with the maximum IHA $=2 * 104 \mathrm{nMs}-1$ corresponds to a high level of stress. Further, the normal condition with $\mathrm{IHA}=1250 \mathrm{nMs}-1$ corresponds to basal or lower histamine levels and the stressed condition is associated with heightened histamine levels and significant reduction in serotonin levels. (C, D) Variation in Si under a two-fold increase and decrease in the parameter of interest while keeping rest of the parameters fixed. Dark red (magenta) bars refer to a two-fold increase (decrease) in the parameter. The 
blue bar refers to Si for the basal condition i.e. when all the parameters are set to their basal value. (C) The Si values for normal conditions are shown. A Si of zero exists for basal values of the parameters, shown here in blue bar. It may also be noticed that spanning a parameter range doesn't cause a significant change in Si. (D) The Si values for the stressed condition are also shown. The basal values of the various parameters are $\mathrm{tHA}=0.8 \mathrm{~s}-1, \mathrm{\tau} 5 \mathrm{HT}=0.8 \mathrm{~s}-1, \mathrm{a}=69.7961 \mathrm{~s}-1, \beta=0.0013 \mathrm{~s}-1, \mathrm{I} \mathrm{HHT}=56.3250$ $\mathrm{nMs}-1$ and IHA $=1250 \mathrm{nMs}-1$ for the healthy condition and IHA $=2{ }^{\star} 104 \mathrm{nMs}-1$ for the stressed condition are obtained by fitting the model to the experimental data. Variation in histamine reuptake rate tHA causes the most significant change in Si. 


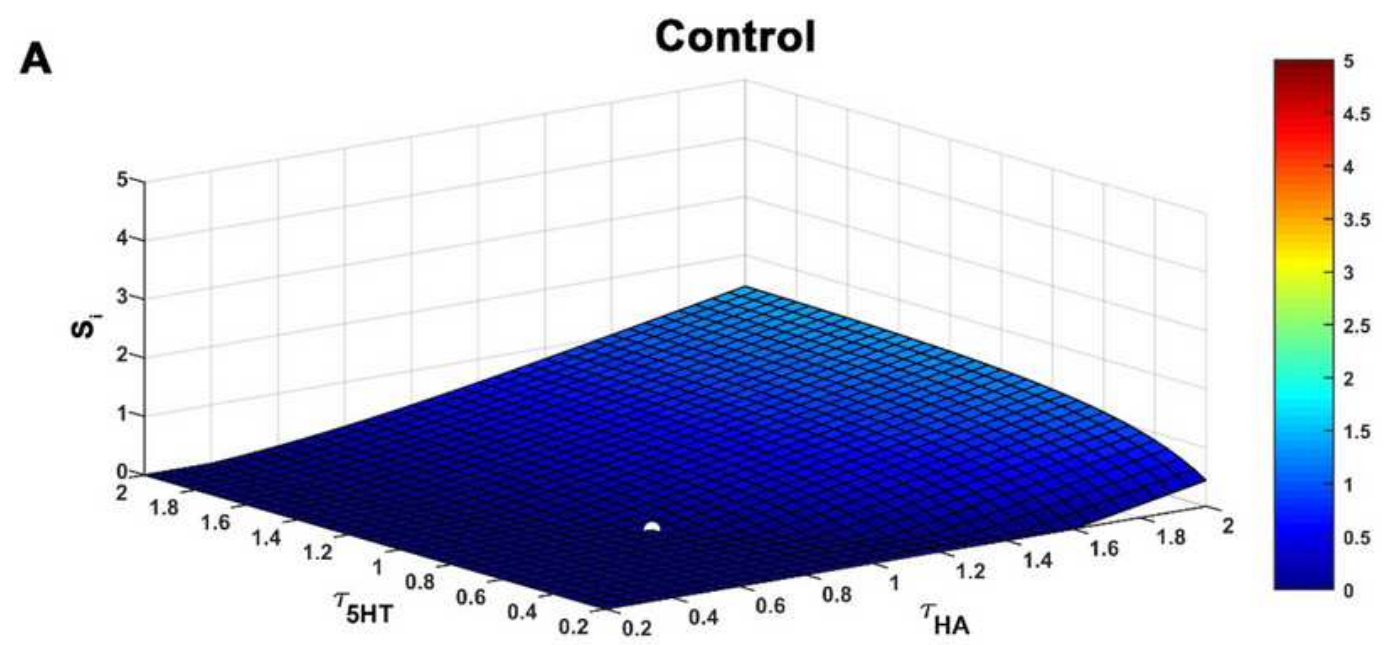

B

\section{Stress}

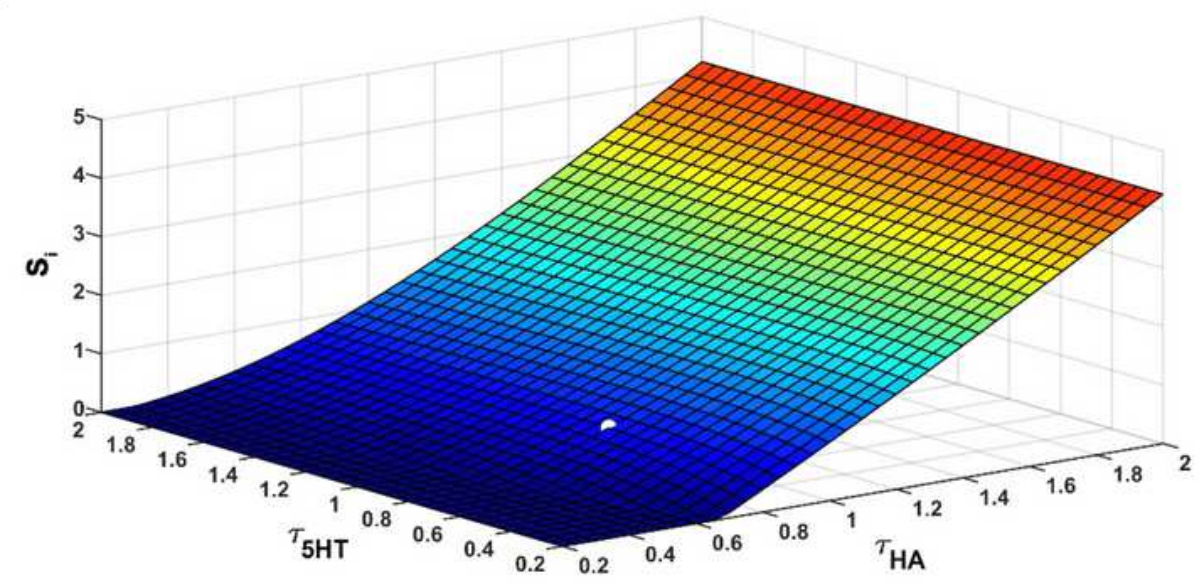

C

\section{Stress Intervention}

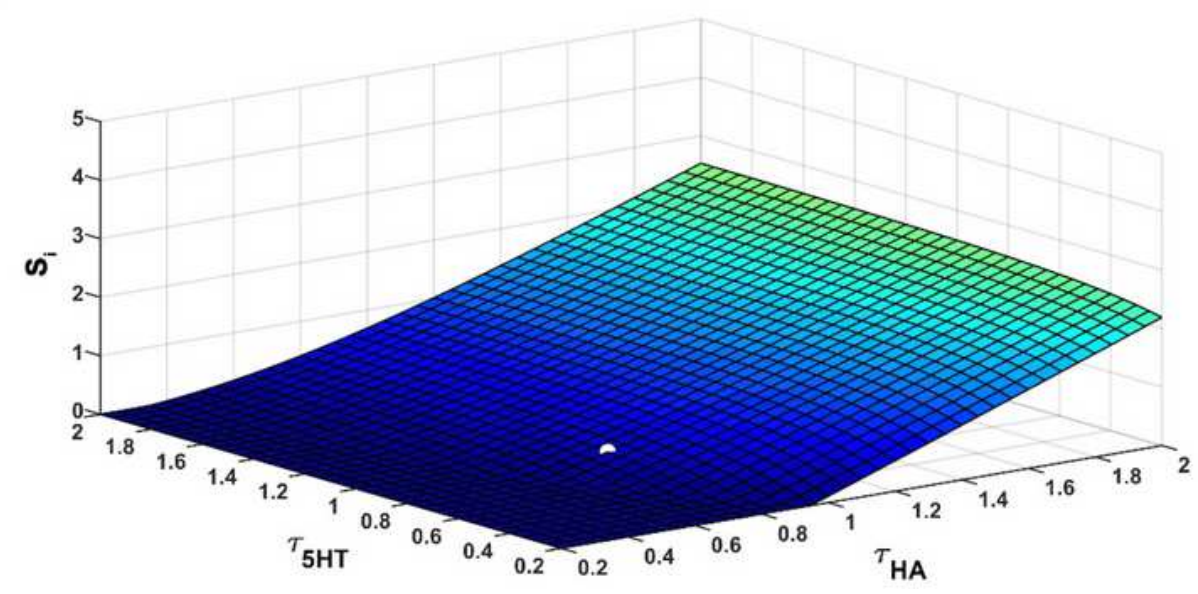

\section{Figure 6}

Administration of SSRIs elevates Stress Index. (A) SSRIs not only cause an increase in serotonin by blocking serotonin reuptake (the known convention) but also block histamine reuptake leading to a concomitant increase in histamine. This impact is realized in the present model through simultaneous increase in equilibrium histamine and serotonin levels reuptake rates, $\mathrm{THA}$ and $\tau 5 \mathrm{HT}$, respectively under (A) control, (B) stress, (C) ESCIT administration conditions. The stress intervention condition is 
associated with a two-fold decrease in tonic histamine supply, IHA which may be achieved through a histamine reducing drug. The white solid circle refers to $\mathrm{Si}$ for basal parameter values. The graded-color bar denotes the increase in stress index (from blue to red) due to changes in histamine and serotonin concentration. It is observed that blocking histamine leads to a reduced $\mathrm{Si}$ in (C). Here, $\tau \mathrm{HA}=0.8 \mathrm{~s}-1$, $\tau 5 \mathrm{HT}=0.8 \mathrm{~s}-1, \mathrm{a}=398 \mathrm{~s}-1, \beta=0.0013 \mathrm{~s}-1, \mathrm{I5HT}=118.75 \mathrm{nMs}-1 . \mathrm{IHA}=1.25^{\star} 104 \mathrm{nMs}-1$ is considered for control condition $(A), I H A=3.88 * 104 \mathrm{nMs}-1$ for the stressed condition $(B)$, and $\mathrm{IHA}=1.94 * 104 \mathrm{nMs}-1$ for the stress intervention condition (C).

A

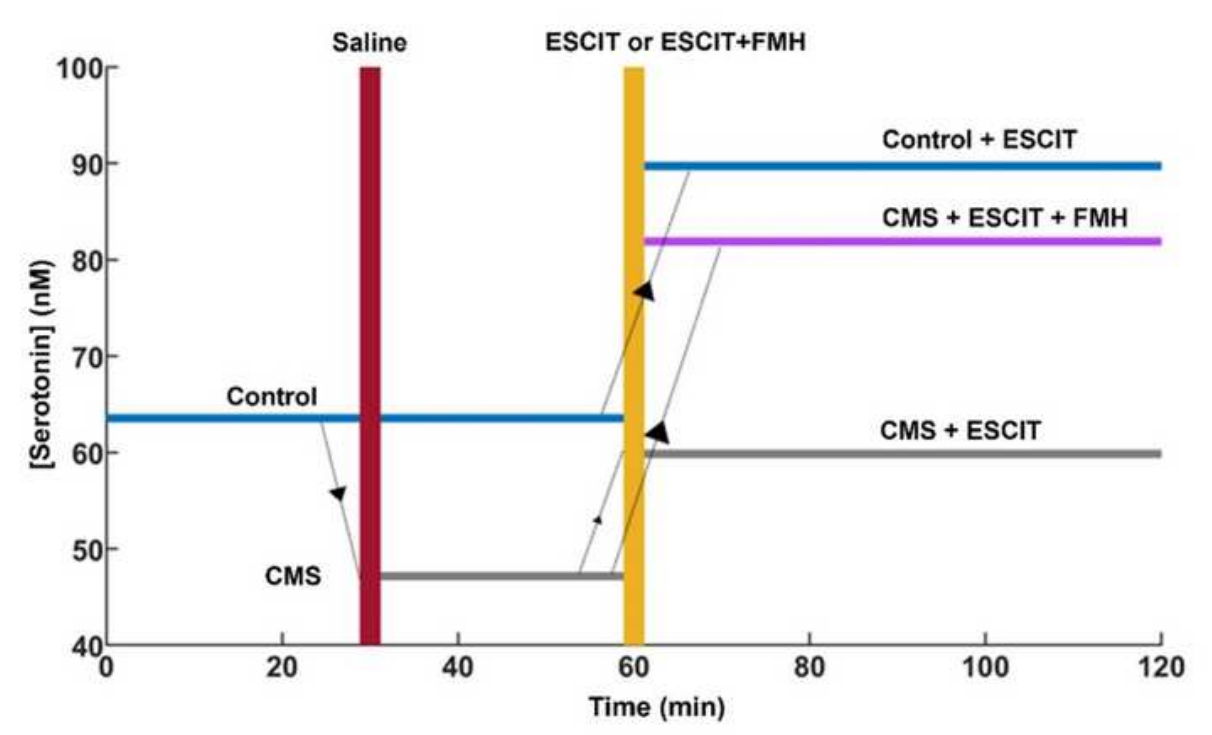

B

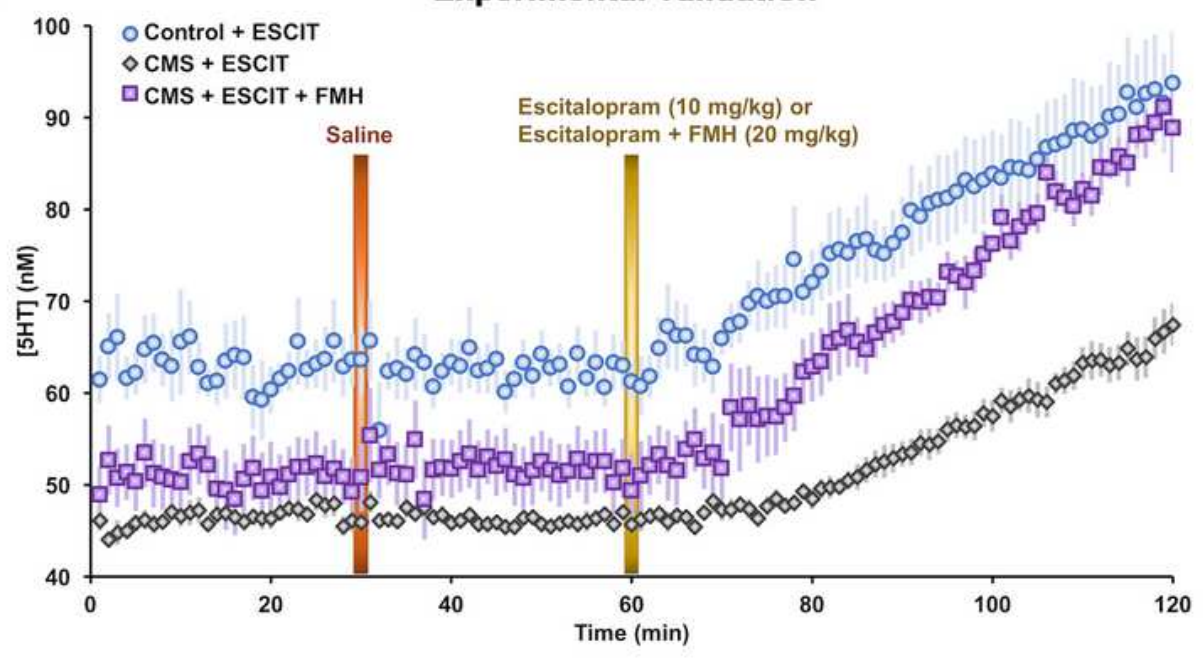

C

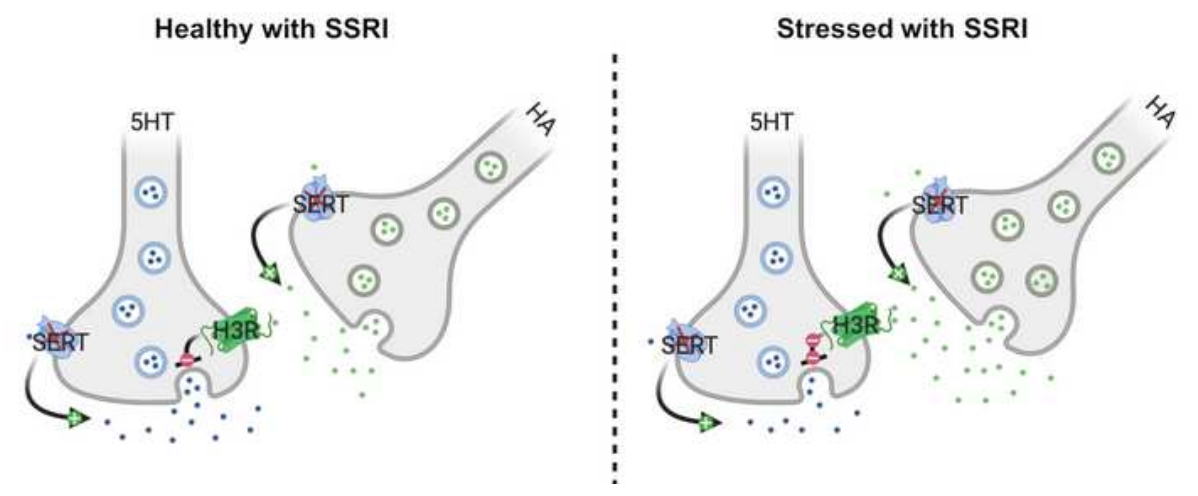




\section{Figure 7}

Pharmacologically targeting hippocampal histamine and serotonin concentrations to alleviate stressinduced changes in serotonin. (A) In the model, three representative mice population are considered: control mice administered the SSRI escitalopram (ESCIT) (in blue), a serotonin elevating drug, chronic mild stress (CMS) mice given ESCIT (in gray) and CMS mice treated with ESCIT and histamine-synthesis blockers a-fluoromethylhistidine (FMH) (in purple). These representative mice population differ from one another based on their serotonin levels and treatment received. It must be noted that our model has been studied at steady state. The time plotted here is just to show a more realistic comparison of our model predictions with the experiments conducted to test our observations. In the model ESCIT administration refers to a two-fold increase in $\tau 5 \mathrm{HT}$ and 1.25 -fold increase in tHA. Further, FMH administration refers to a two-fold decrease in IHA. Here, $\tau H A=0.8 s-1, \tau 5 H T=0.8 s-1, a=398 s-1, \beta=0.0013 s-1,15 H T=118.75$ $\mathrm{nMs}-1$ and $\mathrm{IHA}=1.25 * 104 \mathrm{nMs}-1$ for healthy condition and IHA $=3.88^{\star} 104 \mathrm{nMs}-1$ for the stressed condition. (B) In vivo data showing basal hippocampal serotonin in control mice given saline and then ESCIT (i.p., 10 mg kg-1, n = 7, in blue), CMS-treated mice given saline and then ESCIT (i.p., 0.2 mg kg-1, n $=8$, in gray), and CMS-treated mice given saline and then ESCIT (i.p., $10 \mathrm{mg} \mathrm{kg-1}$ ) and FMH (i.p., $20 \mathrm{mg}$ $\mathrm{kg}-1, \mathrm{n}=5$, in purple). (C) Modified histamine/serotonin schematic showing the influence of an SSRI on the system in control and chronic stress.

\section{Supplementary Files}

This is a list of supplementary files associated with this preprint. Click to download.

- MethodsandSuppFINAL.docx 